\title{
Grandparental availability for child care and maternal labor force participation: pension reform evidence from Italy
}

\author{
Massimiliano Bratti ${ }^{1,2,3,4}$ (D) Tommaso Frattini ${ }^{2,3,4,5,6,7}$. \\ Francesco Scervini ${ }^{8}$
}

Received: 20 July 2017 / Accepted: 6 December 2017 /Published online: 21 December 2017

(C) The Author(s) 2017. This article is an open access publication

\begin{abstract}
In this paper, we exploit pension reform-induced changes in retirement eligibility requirements to assess the role of grandparental childcare availability in the labor force participation of women with children under 15 . Our analysis shows that, among the women studied, those whose own mothers are retirement eligible have a $11 \%$ higher probability of being in the labor force than those whose mothers are ineligible. The pension eligibility of maternal grandfathers and paternal grandparents, however, has no significant effect on the women's labor force participation. We also demonstrate that the eligibility of maternal grandmothers mainly captures the effect of their availability for childcare. Hence, pension reforms, by potentially robbing households of an
\end{abstract}

Responsible editor: Alessandro Cigno

Massimiliano Bratti

massimiliano.bratti@unimi.it

Tommaso Frattini

tommaso.frattini@unimi.it

Francesco Scervini

francesco.scervini@unipv.it

1 European Commission Joint Research Centre (JRC), Via E. Fermi 2749, TP 361, 21027 Ispra, VA, Italy

2 DEMM, Università degli Studi di Milano, via Conservatorio 7, 20122 Milan, Italy

3 IZA, Bonn, Germany

4 LdA, Milan, Italy

5 CReAM, London, UK

6 Dondena Centre for Research on Social Dynamics and Public Policy, Milan, Italy

7 CEPR, London, UK

8 DSPS, Università degli Studi di Pavia, Corso Strada Nuova 65, 27100 Pavia, Italy 
important source of flexible, low-cost childcare, could have unintended negative consequences for the employment rates of women with young children.

JEL Classification $\mathrm{J} 13 \cdot \mathrm{J} 22$

Keywords Grandparental childcare · Maternal employment · Pension reform ·

Retirement

\section{Introduction}

Given the progressive population aging in developed countries, increasing female labor force participation (hereafter, LFP) and employment are paramount if Europe is to meet its 2020 target of $75 \%$ employment among those aged 20-64, a necessary objective for boosting economic growth and ensuring national pension system sustainability. Achieving this goal involves narrowing the employment gender gap, which to different degrees is still substantial in all EU member states but especially high in Southern European countries. In fact, a recent OECD (2012) analysis of labor market gender gaps reports 2011 male versus female employment rates in the 15-64 age group of 65.9 versus $45.1 \%$ in Greece, 64.1 versus $52.8 \%$ in Spain, and 67.5 versus $46.5 \%$ in Italy.

Although several explanations are proposed for the low labor force attachment of women in Southern European countries, the most cited are cultural influences like the "male breadwinner model" and institutional constraints (which, in turn, may also reflect cultural influences). Among the latter, the lack of publicly provided childcare is stressed as a major barrier to women's reconciliation of family with career (Del Boca and Vuri 2007; Del Boca and Sauer 2009). In Italy, for instance, public expenditure on childcare accounts for a tiny $0.2 \%$ of GDP, which is half of the average OECD-30 expenditure (see Fig.x 1). Unfortunately, the need to cope with tight budgetary constraints after the Great Recession has prevented most Southern European countries from increasing the funds allocated to family policies and thus hampered any substantial progress in raising

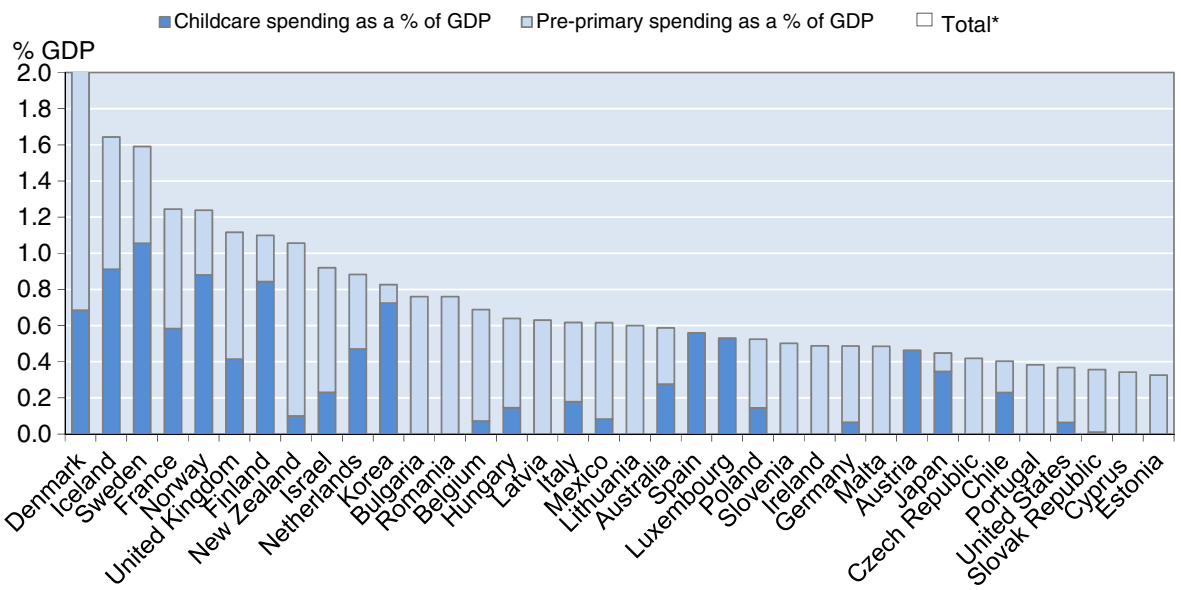

Fig. 1 Public expenditure on childcare and early education services, percent of GDP, 2011. Source: OECD Family Database (http://www.oecd.org/social/family/database.htm), chart PF3.1 
female employment. It is therefore likely that in a context of low or even shrinking public childcare provision, grandparents (and relatives in general) may serve as an important source of affordable childcare for working women. According to Hank and Buber (2009), for instance, about $32 \%$ of European grandmothers are engaged in regular childcare (i.e., almost weekly or more often) with percentages in countries such as Greece, Italy, and Spain almost twice as large as those in Scandinavia. In Italy, a survey run by the Italian National Statistical Institute (ISTAT) in 2005 shows that grandparents remain the main source of childcare when the mother is working. Among 1-2-year-old children of working mothers, about half $(52.3 \%)$ are looked after by grandparents, $13.5 \%$ are enrolled in public nurseries, $14.3 \%$ in private nurseries, and $9.2 \%$ looked after by nannies (ISTAT 2005). In this paper, we assess whether grandparents' potential availability for childcare, proxied by their meeting pension eligibility requirements, has a positive effect on female, and especially maternal, labor force participation. ${ }^{1}$ This question is relevant not only in light of the widespread structural underinvestment in public childcare in many European countries, but also the recent pension reforms introduced in many EU member states. These reforms, by setting stricter retirement eligibility requirements, may have unintended consequences on female employment. For example, we show that raising retirement age and years of contributions, by reducing the supply of low-cost, flexible, informal childcare provided by grandparents, can reduce the labor force participation of mothers. Hence, pension reforms that are not coupled with sufficient investment in public childcare may further exacerbate the already wide intergenerational and gender gaps in employment by reducing the employment of young women relative not only to older women but also to young men, who traditionally bear less of the childcare burden.

The case of Italy is ideal for studying how changes in pension eligibility impact labor force participation because in recent years it has undergone several pension reforms that have gradually increased retirement requirements. For instance, whereas prior to 1992, the 20-year accumulated contribution rule allowed many public sector workers to retire in their 40 s or early 50 s, since then several pension reforms have gradually increased the number of years of contributions required for seniority-based retirement, and raised the minimum age required for age-based retirement to 65 . These pension eligibility rules, which vary over time and according to such factors as gender and employment sector, provide an arguably exogenous variation (see also, Bottazzi et al. 2006; Battistin et al. 2009, 2015; Aparicio-Fenoll and Vidal-Fernandez 2015) used in this paper to identify the effect of grandparental childcare availability on maternal employment.

Our estimates show that mothers of cohabiting children under 15 whose own mothers are eligible for retirement have a 7.1 percentage point higher probability of labor force participation $(+11 \%)$ than those whose mothers are not yet eligible. We interpret this result to mean that grandparental availability for childcare facilitates the labor force participation of women with young children.

\footnotetext{
"In this paper, we use the term "women" to refer to the females whose labor force status is being investigated. Although both parents and parents-in-law are sometimes collectively referred to as "grandparents" (adopting the perspective of the women's children), the women's "mother" and "father" are specifically designated as "maternal grandmother" and "maternal grandfather," respectively, while the "mother-in-law" and "father-inlaw" are labeled "paternal grandmother" and "paternal grandfather."
} 
This interpretation is confirmed by the absence of any such effect for men or for women with no cohabiting children under 15, but a large effect for women with very young children, who have the most intensive childcare needs, and for low-educated mothers or mothers in small municipalities, who have fewer childcare alternatives available in the market. Our baseline results are also robust to several sensitivity checks; in particular, accounting for potential sample selection issues into having a cohabiting child aged 0-14, considering employment instead of LFP, and including controls for additional pathways through which grandparental retirement eligibility may affect female LFP (e.g., income and wealth transfers).

Our paper complements the evidence in Aparicio-Fenoll and Vidal-Fernandez (2015) by exploiting seniority-eligibility rules in addition to age-eligibility rules. This is a nonnegligible improvement because past research has shown that individuals tend to retire as soon as possible (Behaghel and Blau 2012; Gruber and Wise 2007), and reforms increasing age requirements may cause a "run to seniority pension" (Brugiavini and Peracchi 2012; Ardito 2017) increasing the relative incidence of seniority vis-à-vis old-age pensions. As a consequence, the age-eligibility rules exploited in previous papers are likely to be binding only for those grandparents who did not or could not use the seniority rules such as late labor market entrants (e.g., highly educated individuals), grandparents with very discontinuous working lives, or those who did not have to provide childcare (see Rupert and Zanella 2014). The potential endogeneity of individuals' seniority-based eligibility is addressed (i) by controlling for a large set of determinants of grandparents' retirement eligibility available in our data (age, gender, education, and employment sector and type), so that our preferred model is only identified by changes in the retirement rules mandated by pension reforms; and (ii) by not using grandparents' actual years of pension contributions to compute seniority eligibility, but imputing years of contributions based on the average behavior of individuals with the same characteristics. Our results point to the importance of exploiting both sources of eligibility. Indeed, our estimated effects are substantially larger than the comparable (reduced form) estimates reported by Aparicio-Fenoll and VidalFernandez (2015), especially on the sample of women with younger children (15 percentage point vs. -3 percentage point). This difference leads to markedly different conclusions and policy implications on the importance of grandparentprovided childcare.

The remainder of the paper is organized as follows. Section 2 briefly reviews the most relevant empirical literature and highlights our main contributions. Section 3 gives a brief history of the Italian pension laws, whose nature assures exogenous variation in grandparental availability for childcare, and describes our empirical strategy. Section 4 describes the data used in our empirical analysis, and Section 5 investigates the relation between pension eligibility and retirement status. Section 6 reports our primary analytical results while the outcomes of several robustness checks are described in an appendix, after which Section 7 reports some back-of-the-envelope calculations of the potential effect of pension laws on maternal aggregate employment. Section 8 summarizes the main findings and concludes the paper. 


\section{Related literature}

The estimation of the causal effect of grandparent-provided childcare on women's labor supply is fraught with several identification challenges (see Zanella 2017 for a recent review of the literature). One major identification problem is that a simple OLS regression of maternal labor supply on grandparent-provided childcare may lead to biased estimates because this latter is unlikely to be exogenous with respect to the former. At the same time, both the reverse causality of grandparents providing childcare because a woman works and the simultaneous existence of unobservable (or unobserved) characteristics (e.g., grandparental health) that affect female labor supply behavior and informal childcare availability may lead to spurious correlation. One previously attempted solution to this identification issue leverages the arguably exogenous variation in grandparent-provided childcare generated by either the grandparents' being alive or their retirement eligibility. ${ }^{2}$ For example, Arpino et al. (2014) employ data from the 2003 wave of the ISTAT multipurpose "Family and Social Subjects Survey" (FSSS), which collects information on a mother's use of grandparental childcare. By instrumenting the latter with grandparents being alive or not, these authors estimate that using grandparent-provided childcare raises a mother's likelihood of being in the labor market by 32.3 percentage points. ${ }^{3}$ In earlier work, Posadas and Vidal-Fernandez (2013) apply a similar identification strategy to US panel data to demonstrate a positive effect on women's LFP. Their instrumental variable (IV) estimates, however, are much lower $(14.6$ percentage points $)$ and less precise $(p$ value $=0.29)$ than those reported by Arpino et al. (2014) for Italy, partly perhaps because of the two countries' different institutional settings. ${ }^{4}$

Neither of these studies, however, takes into account that surviving grandparents may greatly differ in the amount of time they can devote to childcare, an aspect acknowledged in two recent papers that exploit differences in grandparental labor market participation generated by changes in retirement eligibility rules. In the first, Aparicio-Fenoll and Vidal-Fernandez (2015; hereafter, AFVF) use age-based pension eligibility as an identification source in three waves

\footnotetext{
${ }^{2}$ Other studies proxy grandparental availability for childcare by exploiting variations in their geographic proximity based on the assumption that the closer the grandparents live to their children or children-in-law, the more available they are for childcare (e.g., Compton and Pollak 2014). However, residential choices of both the women and their grandparents may be endogenous. Women who are more labor market oriented, for instance, may more greatly value living close to their parents and having a potential source of low-cost childcare. The same criticism applies to studies that examine the effect on women's labor market outcomes of grandparents residing with the family (Leibowitz et al. 1992; Ogawa and Ermisch 1996; Abendroth et al. 2012) without addressing this arrangement's potential endogeneity. Compton and Pollak (2014) address this endogeneity issue by using a sample of military wives whose husbands' locations are determined by the military. They offer some evidence that military wives residing in their birth state are more likely to be in the labor force.

${ }^{3}$ A similar strategy, although not in an IV setting, was already employed by Del Boca (2002) using data from the Survey on Household Income and Wealth (SHIW). The author proxies informal childcare availability by reports of at least one grandparent being alive, which she then links positively to maternal participation in Italy's labor force.

${ }^{4}$ Based on their individual fixed effects estimates, which they deem the most reliable, Posadas and VidalFernandez (2013) report that grandparental childcare increases women's LFP by 9 percentage points.
} 
(1998, 2003, and 2009) of the FSSS to investigate the effect of grandparental pension eligibility on female fertility and LFP. Using a two-sample, two-stage least squares estimator, they show that the maternal grandmother's LFP decreases her daughter's LFP by 21.4 percentage point in the whole sample. Focusing on grandmother's LFP instead of grandparent-provided childcare implies that their estimate could simultaneously capture alternative mechanisms, namely both grandparent-provided childcare and financial transfers, which may be used by women to buy external childcare. Indeed, the authors explain the surprisingly lower effect (14 percentage point) of grandmother's LFP for the restricted sample of women with children under 3, whose childcare needs are presumably greater, as an indication of working grandmothers transferring more resources to their daughters. The authors also estimate a reduced form model in which the grandmother's lack of pension eligibility is directly included in her daughter's LFP. These estimates, which are comparable with those presented in our paper, produce -5.1 percentage point and -3.4 percentage point effects for the whole and restricted samples, respectively. In the other study, which uses only the 2009 wave of the FSSS, Battistin et al. (2015) exploit pension reform-generated exogenous variation to demonstrate a positive effect of grandparental retirement eligibility on female fertility. To explore potential channels for this effect, they also assess the impact of grandparental pension eligibility on employment, reporting estimated effect ranges between 4 and 2.5 percentage points that are concentrated among women under 35 and decrease with a woman's age.

It is important to highlight certain potential weaknesses in the previous literature using IV estimation. First, instrumental variables require not only that the excluded instruments be exogenous but also that the so-called exclusion restriction assumption hold. The latter implies, for instance, that grandparental deaths should not affect female LFP through channels other than informal childcare provision, conditional on the variables included in the regressions. This assumption may fail in our setting because the monetary transfers that a woman (or her partner) receives from her parents or in-laws-whose effect on her nonlabor income varies her LFP incentives-will likely depend on whether these relatives are alive (dead) or (non)employed. In the case of Posadas and Vidal-Fernandez (2013) and Arpino et al. (2014), for instance, in order for the exclusion restriction to hold, women with deceased parents (in-laws) must have the same nonlabor income availability as those whose parents (in-laws) are still alive. In reality, however, such may not be the case. On the one hand, early loss of a parent (in-law) may entail lower wealth accumulation and lower expected intervivo transfers and inheritances, generating an income or wealth effect on labor supply. On the other hand, if one parent (or in-law) dies, a woman may immediately receive some wealth in the form of inheritance, which could soften household budget constraints, especially when capital markets are imperfect, and the additional resources might partly be used to buy costly external childcare. Thus, the effect of cash and wealth transfers may reinforce or countervail that of grandparent-provided childcare, although in general, it is difficult to assess the bias of the estimates exante when this channel is neglected.

The IV strategy used by AFVF (2015), which estimates the effect of grandmother's LFP, like we already stressed mixes the effects of childcare 
and monetary and wealth transfers. Since the authors have no information on such variables, they can only estimate a "gross" effect. In this respect, our data set permits us to include explicit proxies of intervivo transfers and inheritance received by the women and their partners (Section 6.2), allowing us to disentangle the childcare provision channel from other potential effects of grandparental pension eligibility.

Other contributions with respect to the extant literature include the fact that although our identification strategy is similar to that in AFVF (2015), ours uses both age-based retirement pension and contribution-year-based seniority pension rules to define grandparental pension eligibility. At the same time, in contrast to Battistin et al. (2015), our definition of retirement pension eligibility does not assume continuous working lives which, although probably innocuous for grandfathers, could lead to a substantial overestimation of grandmother eligibility given the share of mothers who experience career interruptions or even permanent exit from the labor market around childbearing (Pronzato 2009). ${ }^{5}$ Any such overestimation (or underestimation) of grandparental eligibility (a misclassification error) may lead to an attenuation bias in the estimates (Lewbel 2007). Battistin et al. (2015) also use retrospective data to reconstruct lifecycle labor supply, which, as the authors acknowledge, may be problematic for analyzing labor market behavior because of possible recall errors. By considering only information on mothers' current employment, we minimize the impact of this recall bias.

A further more substantive difference from both AFVF (2015) and Battistin et al. (2015) is that instead of considering the effect on LFP of all women, we focus only on mothers. Although both effects are of interest, they are potentially different. Our study thus throws light on the potential effect of raising retirement eligibility requirements on the LFP of women who are already mothers via deprivation of grandparental childcare. Previous research, in contrast, estimates the labor supply effect as the average effect on the whole female population, both mothers and nonmothers. This average effect, however, could differ if, for instance, the reforms induced the former to decrease LFP in response to losing grandparental childcare but motivated the latter to postpone or reduce fertility and so increase their labor supply. ${ }^{6}$ The total effect on women's LFP would then be ambiguously signed. Other important differences are our inclusion of women with deceased grandparents and allowance for differential effects on maternal LFP of the childcare availability of grandparents who never worked versus those who worked and are now pension eligible. As discussed in the next section, we expect these two grandparental caregiver types to have very different effects on female LFP, a theoretical prediction that is indeed supported by the empirical analysis (see Section 7).

\footnotetext{
${ }^{5}$ Also problematic is neglecting employment sector and type and/or applying private sector rules to all grandmothers, since it leads to a less precise measure of retirement eligibility.

${ }^{6}$ Some recent studies using presumably exogenous variation in motherhood or family size to estimate the "motherhood" or "child" penalty include Bailey (2006), Cruces and Galiani (2007), Cristia (2008), and Càceres-Delpiano (2012).
} 


\section{Using pension reforms to identify the effect of grandparental childcare}

\subsection{A brief history of pension reforms in Italy}

Three major reforms were implemented in Italy during the 1990s to control severe imbalances in the public pension system. Prior to 1992, both retirement requirement and benefit amounts were very generous, with private sector workers allowed to retire at 60 (55 for women) with at least 15 years of contributions (age-based retirement pension) or after 35 years of contributions, independent of age (seniority pension). ${ }^{7}$ The amount of the benefit was based both on contributory years and earnings received during the last working years, with a private sector worker receiving $2 \%$ of the average earnings of the last 5 years before retirement for every year of contribution paid. The steep earning profiles of most workers resulted in very generous benefits, leading to a record 1992 benefits/GDP ratio of 16\%, which raised the issue of system sustainability and triggered changes in the retirement age and benefits of current and future workers.

In the more general framework of public deficit reduction, the first emergency attempt to balance the pension system budget was the so-called Amato reform (D.Lgs.503/1992), which gradually increased both age and contribution requirements by 5 years. Two years later, the Dini reform (L.724/1994 and L.335/1995) reorganized the system so substantially as to imply a transition from earnings-based to contributionbased benefit computation while decreasing the age requirement but increasing the contribution requirement. It also introduced and regulated a parallel (voluntary) private pension system, which, however, applied only to individuals starting their first job after 1995 or voluntarily opting for the new system. ${ }^{8}$ Finally, the Prodi reform (L.449/1997) modified the part of the Dini reform targeted at older workers, slightly increasing the age requirements and harmonizing the rules for public and private sector employees and self-employed workers.

Table 1 summarizes the minimum age and contribution requirements set by the different reforms for private employees, public employees, and self-employed workers, which we use in the paper to define individual eligibility for a state pension. ${ }^{9}$ As previously explained, workers had some discretion in choosing the requirements-benefits scheme, so for each of the three laws, we report the minimum requirements for every year (half-year for those enacted by July 1) according to gender and employment sector and type. The first column refers to the 1992 Amato reform; the second to the 1995 Dini reform for older workers, as modified by the 1997 Prodi reform; and the third to the 1995 Dini reform for the most recent cohorts of workers. These latter requirements are relevant because older individuals could opt for this system. To illustrate, before the 1992 Amato reform, a 62-year-old male working in the public sector with 30 years of contributions was pension eligible based on both age (60 for public sector workers) and seniority (20 years for public sector workers). In 1993, after the Amato reform, an identical individual was eligible only for a seniority pension because the retirement age had

\footnotetext{
${ }^{7}$ Requirements for public sector workers were even more generous (see Table 1).

${ }^{8}$ Only in 2012 (Fornero reform, D.L.201/2011) was the contribution-based system (partially) extended to all workers. This reform, however, is outside our period of analysis.

${ }^{9}$ Workers in certain sectors (e.g., arduous or hazardous jobs like mining or long-distance driving) might have different requirements, but we disregard these in our paper.
} 


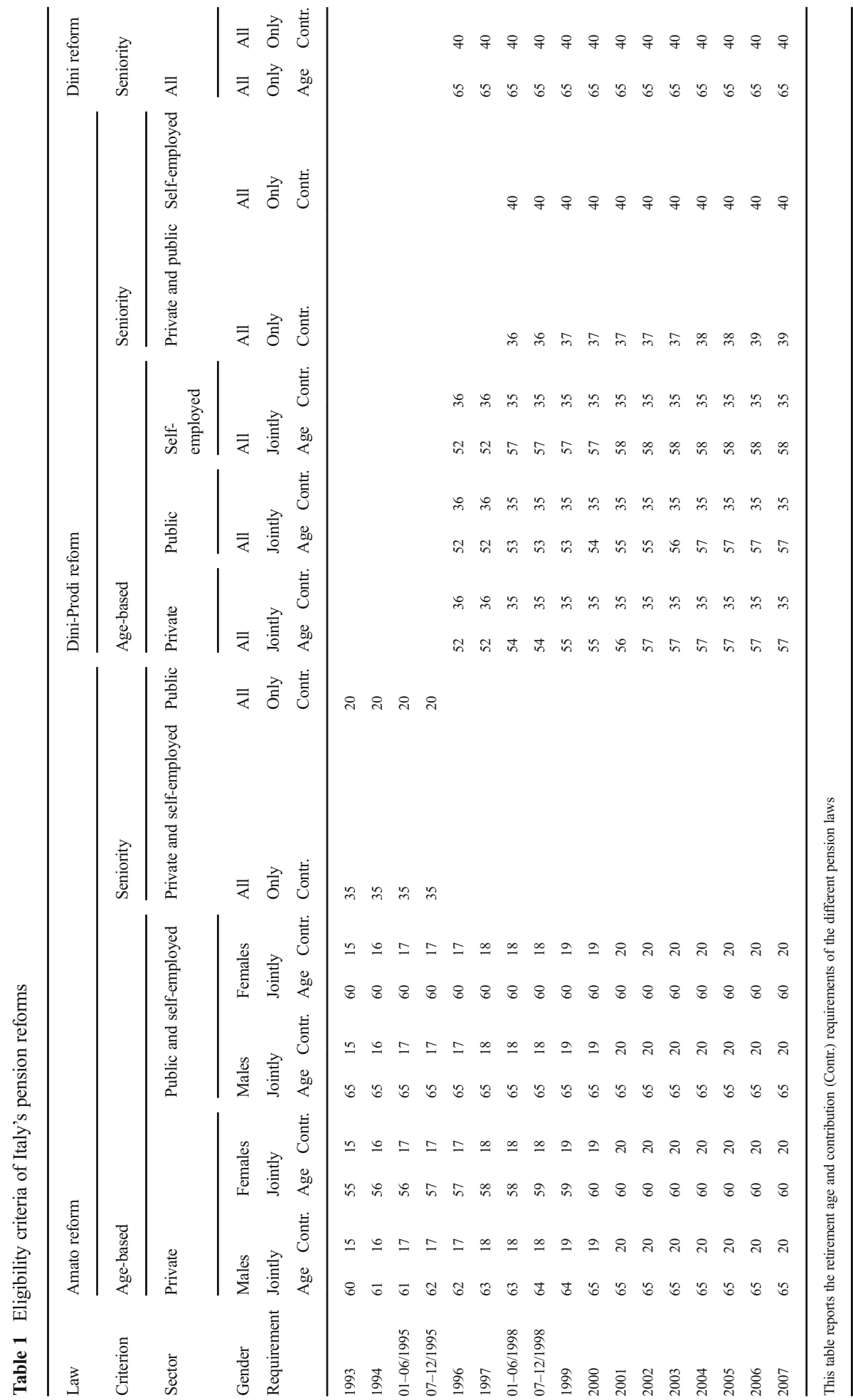


been raised. After 1996, an individual with the same characteristics would have been ineligible based on age (Amato), contribution years (Dini-Prodi), or both (Dini). Hence, consistent with the opportunity to choose the requirement, we assume that workers are eligible for a state pension whenever they satisfy at least one of the three criteria.

\subsection{Empirical strategy}

Although we seek to reveal how grandparental childcare determines mothers' LFP, our data contain no information on whether and how much time grandparents spend with their grandchildren (a variable that would anyway be endogenous to women's labor market outcomes). Therefore, rather than directly relating women's employment to grandparental childcare, we correlate the mothers' LFP with their parents' and in-laws' potential availability for childcare by estimating a linear probability model of the following form:

$$
y_{i t}=\alpha+\sum_{k=1}^{4}\left(\beta_{1}^{k} N W_{i t}^{k}+\beta_{2}^{k} E L_{i t}^{k}+\beta_{3}^{k} N E L_{i t}^{k}\right)+\gamma^{\prime} X_{i t}+\tau_{r t}+u_{i t}
$$

where $y_{i t}$ is a dummy capturing whether woman $i$ is in the labor force or not in year $t$. Our main variables of interest are the three dummy variables $N W_{i t}^{k}, E L_{i t}^{k}, N E L_{i t}^{k}$ which capture the potential availability for childcare of each relative $k=1, \ldots 4$, when 1 and 2 are the woman's mother and mother-in-law, respectively, and 3 and 4 , her father and father-in-law. More specifically, $N W_{i t}^{k}$ is equal to 1 if individual $k$ is alive and has never worked (i.e., has always been out of the labor force) and 0 otherwise, and $E L_{i t}^{k}\left(N E L_{i t}^{k}\right)$ is an indicator variable equal to 1 if individual $k$ is alive and (in)eligible for a state pension (based on the pension eligibility rules outlined in the previous subsection). If individual $k$ is not alive, all three variables take the value 0 . We also control for all time variant region-specific factors that might affect female employment by including region by year fixed effects $\left(\tau_{r t}\right)$, which, among other things, capture differences in the socioeconomic environment (e.g., unemployment) and public childcare provision. Finally, $X_{i t}$ is a vector of individual-level variables that may also affect women's labor supply and employment, including age and education of individual $i$, and her parents and in-laws, partner's income and education, and size of the municipality of residence. In the most saturated version of the model, this vector also includes the grandparents' employment sector (private or public) and type (employee or self-employed).

We exploit two sources of variation to identify the effect of interest: The first is crosssectional variation determined by differences in the grandparents' gender, education, and employment sector and type. These latter are generally associated with different ages of entry into the labor market (and thus years of pension contributions conditional on age), as well as different retirement ages even under the same laws (which tend to favor public employees and women). The second is time variation resulting from the pension rule changes introduced by the different reforms passed during our estimation period. In addition to estimating models that exploit each of these two variations, we also compute a more saturated model including all factors determining the grandparental eligibility status, meaning that identification comes only from time variations in the reform-induced eligibility rules. This saturated model enables comparison of like with like; for example, women with parents and in-laws having exactly the same characteristics but whose retirement eligibility status 
varies because of the law in place at the time. It also controls for grandparent characteristics that, in addition to determining their eligibility status, may also have a direct effect on female employment or be proxies of grandparents' career orientation (e.g., age, gender, education, and employment sector and type). ${ }^{10}$ It is worth noting that including in the regressions the determinants of the predicted contribution years we are de facto controlling also for the latter, which is a linear combination of the former and thus cannot be included in the regression.

We are primarily interested in the role of grandparents as potential providers of childcare and estimate accordingly Eq. (1) on a sample of women with young children. Our estimation sample includes every woman aged 20-49 who has at least one child under 15 living in the household. As a validity check, we also estimate it for the sample of women in the same age range who have no children under 15 living in the household and for the sample of their male partners. We focus our attention on the coefficients $\beta_{1}^{k}, \beta_{2}^{k}, \beta_{3}^{k}$, which (multiplied by 100 ) respectively indicate by how many percentage points a mother is more or less likely to participate in the labor force if her relative $k$ has always been out of the labor force, is eligible for state pension and thus potentially retired from the work force, or is not yet eligible for state pension and thus potentially still employed (or job hunting) relative to the case in which $k$ is dead. Given the predominance of women in childcare provision, we expect to find a positive effect of the availability of maternal and paternal grandmothers for childcare on the women's LFP probability but a lower (or no) effect of grandfathers' availability.

Unlike most previous studies, rather than focusing only on the childcare availability of maternal grandmothers, we examine that of all grandparents to avoid any omitted variable bias from its correlating with maternal grandmother availability (e.g., because of similar characteristics like age or education) and affecting women's LFP. On the other hand, considering the aggregate number of available grandparents could hide heterogeneous effects across grandparents, so for this reason we consider the potential availability for childcare of each grandparent individually. We also include in the estimation sample both women whose parents or in-laws were not alive at the time of interview and those whose parents or in-laws had never participated in the labor market. These two characteristics enable us to not only compute the effect on women's employment of not having living parents and/or in-laws, but also to test for the presence of heterogeneous effects from parents or in-laws who are available either because they never worked or because they worked in the past and are now retired. These two groups may in fact have very different effects on women's LFP. We expect that the higher the share of dead grandparents who ever worked, the more $\beta_{1}^{k}$ will capture cultural effects in addition to the childcare availability effect. In particular, an intergenerational correlation is possible between a grandmother's employment and her daughter's, reflecting either unobservable variables correlated across generations or a true causal relation (e.g., a gender role model). ${ }^{11}$ Conversely, any negative intergenerational correlation between a woman's LFP and her mother's never having participated in the labor market

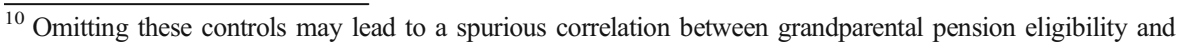
female LFP. However, the estimates obtained with the saturated models are robust to the presence of timeinvariant unobservable grandparent characteristics that drive their educational and employment choices and may also be correlated with female employment. The main assumption is that grandparents who made the same educational and employment choices have similar unobservable characteristics.

${ }^{11}$ See, for instance, Farre and Vella (2013).
} 
may be partly countervailed by the positive effect produced by the latter's provision of informal childcare. The sign of the net effect is therefore an empirical question. Because it is generally hard to find a convincing exogenous source of variation in parental (especially, maternal) lifetime LFP, rather than attaching a strictly causal interpretation to the estimate of $\beta_{1}^{k}$, we consider it only suggestive of potential heterogeneous effects by source of availability. Instead, our main parameter of interest is $\beta_{2}^{k}-\beta_{3}^{k}$, the difference between retirement eligible and ineligible parents or in-laws (who ever worked). These two groups, although very similar in terms of the unobservable variables driving labor force attachment, differ only in their pension rule-induced employment status. We thus interpret this difference causally.

Three other features of our analysis are worth noting. First, unlike those in IV-based studies, our estimation strategy does not require that the grandparent's retirement eligibility has only an indirect effect on women's LFP via grandparental childcare. Rather, part of the reduced form (gross) effect estimated of the grandparents' retirement eligibility on the women's LFP may be produced by additional causal pathways and not exclusively by grandparental childcare. Therefore, to evaluate the relevance of this latter, we implement several placebo tests; in particular, an estimation of Eq. (1) that assesses whether the effects are larger for individuals with a greater need for childcare than for those who need it less (e.g., women vs. men, women with young children vs. other women). Second, unlike previous researchers, we are able to include control variables that capture certain alternative pathways through which grandparental pension eligibility may affect female LFP, in particular, intervivo transfers and inheritances. Lastly, by focusing on parental and in-law retirement eligibility and not on current retirement status (an endogenous choice variable), we are able to address a potential reverse causality bias; namely, that some grandparents may anticipate their retirement to take care of their grandchildren whose mothers are working (Lumsdaine and Vermeer 2014). ${ }^{12}$

Additionally, note that since not all eligible grandparents actually decide to retire, and not all retired grandparents provide childcare to their children's family, our paper provides intention-to-treat (ITT) estimates, which must be interpreted as lower bound estimates of the effect of grandparent-provided childcare on maternal employment. In case of effect heterogeneity, IV and ITT estimates provide effects for the individuals affected by the instrument (compliers), namely retirement eligibility. Given the tendency in Italy of individuals to retire as soon as they become eligible (e.g., Brugiavini and Peracchi 2012), the complier population is large enough to be of policy interest.

\section{Data}

Our analysis is based on data from the SHIW, ${ }^{13}$ administered by the Bank of Italy every 2 years ${ }^{14}$ to a rotating panel of 8000 households (approximately 24,000

\footnotetext{
${ }^{12}$ More generally, Ho (2015) and Rupert and Zanella (2014), among others, show that grandparents' labor supply may be affected by the presence of grandchildren.

13 "Indagine sui bilanci delle famiglie italiane" (Banca d'Italia).

${ }^{14}$ Except for a 3-year interval between 1995 and 1998.
} 
individuals) per year. In addition to focusing on labor market and income-related issues, the survey also gathers information on such relevant topics as education, sociodemographics, consumption, and dwelling characteristics. Besides providing full information on all household members, household heads and their partners also report the birth year, labor market status, educational attainment, and alive or dead status of their parents, ${ }^{15}$ which we use to analyze grandparental availability for childcare. Because of data availability and comparability, we focus on the seven waves covering 1993-2006, for a total potential population of 55,163 households.

Because the relevant survey unit in the SHIW is the household, for every unit in the sample we use both household-specific (e.g., residential region, household size and composition) and individual-specific (e.g., demographics, education, labor market outcomes, income) variables for all household members. We also exploit the information on the household heads and their partners' parents. To study the effects of grandparent availability on maternal labor market outcomes, however, we must restrict our sample to a subset of relevant households containing a cohabiting couple who are potential or actual parents. We therefore select all households that include two partners, one a female aged 20-49 for whom we have complete information on both the dependent and independent variables. This selection reduces the sample to 13,443 couples, $8402(62.5 \%)$ of whom are parents to at least one child younger than 15 living in the household, while the remaining 5041 couples $(37.5 \%)$ either have no offspring or have only children older than 14 or living outside the household.

Table 2 reports the summary statistics for our sample. The women are on average younger than their partners by about 3.5 years, slightly more educated, with a considerably lower LFP rate, about $53 \%$ for females versus $98 \%$ for males. Interestingly, the female participation rate increases with the age of the children: from $57 \%$ for women with no children or children older than 14 in the household to $52 \%$ for women with children younger than 6 . The grandmothers in the sample are consistently about 4 years younger than the grandfathers, and the maternal grandparents are 4 years younger than both paternal grandparents. The grandmothers, however, are less educated than their partners, and less than $30 \%$ of them have ever worked, versus about $93 \%$ for grandfathers. The share of grandparents that are not alive also varies substantially, from a minimum of $15 \%$ for maternal grandmothers to a maximum of $42 \%$ for paternal grandfathers. These differences result from the different birth cohorts: grandfathers are older than grandmothers and men older than women, so that paternal grandfathers are the least likely and maternal grandmothers the most likely to be alive.

\section{Pension eligibility and retirement}

In this paper, we seek to assess the importance of informal childcare provision by grandparents, proxied by their potential availability, on maternal LFP. As described in

\footnotetext{
${ }^{15}$ For 1998, information on whether grandparents were alive is missing, so for that year, we exploit the panel dimension of SHIW and recover, where possible, the information from other waves.
} 
Table 2 Sample summary statistics

\begin{tabular}{|c|c|c|c|c|c|c|c|c|}
\hline \multicolumn{9}{|c|}{ Panel A: women and their partners } \\
\hline & \multicolumn{2}{|l|}{ Women } & \multicolumn{6}{|l|}{ Men } \\
\hline & Freq. & $\%$ & Freq. & \multicolumn{5}{|l|}{$\%$} \\
\hline $\begin{array}{l}\text { In labor force } \\
\quad \text { (children 0-14) }\end{array}$ & 4466 & 53.15 & \multirow[t]{4}{*}{8224} & \multicolumn{5}{|l|}{97.88} \\
\hline $\begin{array}{l}\text { In labor force } \\
\quad \text { (children } 0-10)^{*}\end{array}$ & $3450 / 6479$ & 53.25 & & & & & & \\
\hline $\begin{array}{l}\text { In labor force } \\
\quad(\text { children } 0-5)^{*}\end{array}$ & $1989 / 3803$ & 52.30 & & & & & & \\
\hline $\begin{array}{l}\text { In labor force } \\
\text { (no children } 0-14)^{*}\end{array}$ & $2893 / 5041$ & 57.39 & & & & & & \\
\hline $\begin{array}{l}\text { Employed } \\
\quad \text { (children 0-14) }\end{array}$ & 4253 & 50.62 & \multirow[t]{4}{*}{7912} & \multicolumn{5}{|l|}{94.17} \\
\hline $\begin{array}{l}\text { Employed } \\
\quad \text { (children 0-10)* }\end{array}$ & $3272 / 6479$ & 50.50 & & & & & & \\
\hline $\begin{array}{l}\text { Employed } \\
\quad(\text { children } 0-5)^{*}\end{array}$ & $1878 / 3803$ & 49.38 & & & & & & \\
\hline $\begin{array}{l}\text { Employed } \\
\text { (no children } 0-14 \text { )* }\end{array}$ & $2772 / 5041$ & 54.99 & & & & & & \\
\hline Lower secondary or less & 4028 & 47.94 & 4285 & \multicolumn{3}{|l|}{51.00} & & \\
\hline Upper secondary & 3463 & 41.22 & 3199 & \multicolumn{3}{|l|}{38.07} & & \\
\hline \multirow[t]{2}{*}{ Tertiary or above } & 911 & 10.84 & 918 & \multicolumn{3}{|l|}{10.93} & & \\
\hline & Obs. & Mean (SD) & Obs. & \multicolumn{3}{|l|}{ Mean (SD) } & & \\
\hline Age & 8402 & $37.0(5.97)$ & 8402 & \multicolumn{3}{|l|}{$40.55(6.60)$} & & \\
\hline Income & 8402 & $6932(9111)$ & 8402 & \multicolumn{3}{|l|}{$21,204(21,457)$} & & \\
\hline \multicolumn{9}{|l|}{ Panel B: grandparents } \\
\hline & \multicolumn{2}{|l|}{ Mothers } & \multicolumn{2}{|c|}{ Mothers-in-law } & \multicolumn{2}{|c|}{ Fathers } & \multicolumn{2}{|c|}{ Fathers-in-law } \\
\hline & Freq. & $\%$ & Freq. & $\%$ & Freq. & $\%$ & Freq. & $\%$ \\
\hline Not alive & 1247 & 14.84 & 1797 & 21.39 & 2806 & 33.40 & 3532 & 42.04 \\
\hline $\begin{array}{l}\text { Alive and never } \\
\text { worked }\end{array}$ & 4775 & 56.83 & 4626 & 55.06 & 126 & 1.50 & 106 & 1.26 \\
\hline Alive and eligible & 1715 & 20.41 & 1603 & 19.08 & 3686 & 43.87 & 3699 & 44.03 \\
\hline Alive and ineligible & 665 & 7.91 & 376 & 4.48 & 1784 & 21.21 & 1065 & 12.68 \\
\hline $\begin{array}{l}\text { Lower secondary } \\
\text { or less }\end{array}$ & 7685 & 91.47 & 7795 & 92.78 & 7335 & 87.30 & 7482 & 89.05 \\
\hline Upper secondary & 576 & 6.86 & 491 & 5.84 & 752 & 8.95 & 620 & 7.38 \\
\hline Tertiary or above & 141 & 1.68 & 116 & 1.38 & 315 & 3.75 & 300 & 3.57 \\
\hline Private sector & 1980 & 23.57 & 1868 & 22.23 & 6526 & 77.67 & 6580 & 78.31 \\
\hline Public sector & 534 & 6.36 & 417 & 4.96 & 1280 & 15.23 & 1310 & 15.59 \\
\hline Never worked & 5888 & 70.08 & 6117 & 72.80 & 596 & 7.09 & 512 & 6.09 \\
\hline \multirow[t]{2}{*}{ Self-employed } & 822 & 9.78 & 807 & 9.60 & 2129 & 25.34 & 2323 & 27.65 \\
\hline & Obs. & Mean (SD) & Obs. & Mean (SD) & Obs. & Mean (SD) & Obs. & Mean (SD) \\
\hline Age & 8402 & $65.7(9.12)$ & 8402 & $69.0(9.47)$ & 8402 & $69.6(9.56)$ & 8402 & $73.1(10.07)$ \\
\hline
\end{tabular}

Except for the variables marked with an asterisk, whose sample size is reported next to the frequency, statistics are reported for the baseline sample of 8402 women aged 20-49 who have at least one child under 15 living in the household

Section 3, we divide the grandparents' potential availability into four categories: not alive, never having worked $(N W)$, or in the labor market and either pension eligible 
$(E L)$ or pension ineligible $(N E L)$. Because the SHIW asks respondents directly about their parents' labor market participation, age, birth year, and employment sector and type, we have all the information needed to determine pension eligibility, except for years of contribution. To derive this variable, we exploit the fact that the SHIW does record years of pension contributions for all individuals interviewed. First, we regress the actual contribution years on a set of individual characteristics (gender, age, education, employment sector and type, year, and region) available for both the grandparent cohort ${ }^{16}$ and the surveyed individual cohort and then predict the grandparents' years of contribution on the basis of the estimated coefficients. The regression results are reported in Appendix 1. Once these predictions are obtained, we have all the necessary information to determine whether every grandparent satisfies at least one of the pension requirements and is thus eligible or ineligible for a pension. All regressions using retirement eligibility based on predicted contribution years are bootstrapped (1000 replications) to account for the generated regressors.

We test pension eligibility as a valid predictor of retirement status by running simple regressions of actual individual retirement status of all surveyed individuals (albeit separately for men and women) on both a constant and imputed pension eligibility indicator. The coefficients estimated on this eligibility indicator are $0.719(\mathrm{SE}=0.006)$ for men and $0.857(\mathrm{SE}=0.005)$ for women, ${ }^{17}$ which, when considered together with our main results (reported below), support the validity of pension eligibility as a predictor of potential childcare availability based on actual retirement.

As already emphasized, rather than relying solely on individual age to define pension eligibility (as in AFVF 2015), we exploit both age-based retirement pension rules and seniority pension rules by combining age with sector of employment, type of activity, and predicted years of contribution. This is a major improvement in identification strategy not only because many of the formerly employed individuals in the grandparent cohort began working at a very young age but because a relevant share of grandparents not meeting the retirement age condition are likely to satisfy the seniority pension criterion of contribution years. In fact, Table 3 does indeed reveal a notable percentage of grandparents eligible based on the contribution requirement while still not meeting the age criterion: $30.5 \%$ of fathers, $28.6 \%$ of mothers, $33.5 \%$ of fathers-in-law, and $33.2 \%$ of mothers-in-law. Thus, neglecting the seniority pension criterion would lead to a substantial underestimation of grandparental eligibility, potentially reducing the estimated impact of pension eligibility on female LFP.

\footnotetext{
${ }^{16}$ Parents' (in-laws') sectors and types of employment are measured when they had the same age as the respondent (spouse). In case they were unemployed at that time, the characteristics of the last job are reported.

${ }^{17}$ Potential eligibility is a better predictor of actual retirement for women than for men, which suggests that (because of special rules for hazardous jobs, as stressed in footnote 9) men anticipate or postpone retirement with respect to pension eligibility, while women are more tied to it. Men could decide to postpone retirement with respect to the minimum eligible age more frequently than women for several reasons, including higher income, a good enough health status to work, social norms, and/or a higher psychological costs of retirement.
} 
Table 3 Eligibility by different criteria

\begin{tabular}{|c|c|c|c|c|}
\hline & & & \multicolumn{2}{|c|}{ Eligibility according to age criterion only } \\
\hline & & & Ineligible & Eligible \\
\hline \multirow[t]{16}{*}{ Eligibility } & Father & Ineligible & 984 & 670 \\
\hline & & $(\%)$ & 17.99 & 12.25 \\
\hline & & Eligible & 1668 & 2148 \\
\hline & & $(\%)$ & 30.49 & 39.27 \\
\hline & Mother & Ineligible & 491 & 174 \\
\hline & & $(\%)$ & 20.63 & 7.31 \\
\hline & & Eligible & 681 & 1034 \\
\hline & & $(\%)$ & 28.61 & 43.45 \\
\hline & Father-in-law & Ineligible & 548 & 433 \\
\hline & & $(\%)$ & 11.50 & 9.09 \\
\hline & & Eligible & 1595 & 2188 \\
\hline & & $(\%)$ & 33.48 & 45.93 \\
\hline & Mother-in-law & Ineligible & 237 & 139 \\
\hline & & $(\%)$ & 11.98 & 7.02 \\
\hline & & Eligible & 657 & 946 \\
\hline & & $(\%)$ & 33.20 & 47.80 \\
\hline
\end{tabular}

The table shows eligibility according to age and contribution criteria and eligibility according to age criterion only. Sample size is lower than 8402 since eligibility can only be computed for individuals who are alive and ever participated in the labor force

\section{Effect of grandparental availability on maternal labor force participation}

\subsection{Main results}

Table 4 reports the results of estimating Eq. (1) for a sample of women aged 20-49 who are either household heads or partners and mothers to at least one child under 15 living in the household. In all cases, the columns reporting the different specifications display the estimated coefficients on the three dummy variables $N W, E L$, and $N E L$ for the woman's mother (maternal grandmother), mother-in-law (paternal grandmother), father (maternal grandfather), and father-in-law (paternal grandfather). Column (1) lists the outcomes for the basic specification, which includes only these 12 variables of interest together with region-by-year fixed effects and dummies for municipality size $(<20,000,20,000-40,000,40,000-500,000,>500,000$ inhabitants). Column (2) reports the results for an enriched specification that controls for grandparental educational level (up to lower secondary, upper secondary or tertiary, and above), which may proxy for downstream monetary transfers to women, a major channel through which working grandparents may affect women's LFP. It also controls for grandparents' age, which in addition to affecting their pension eligibility may also affect their health status and thus a daughter(-in-law)'s LFP. Column (3) adds in a quadratic form for the woman's age and dummies for her educational level, which may significantly affect her LFP probability. Column (4) then integrates controls for 


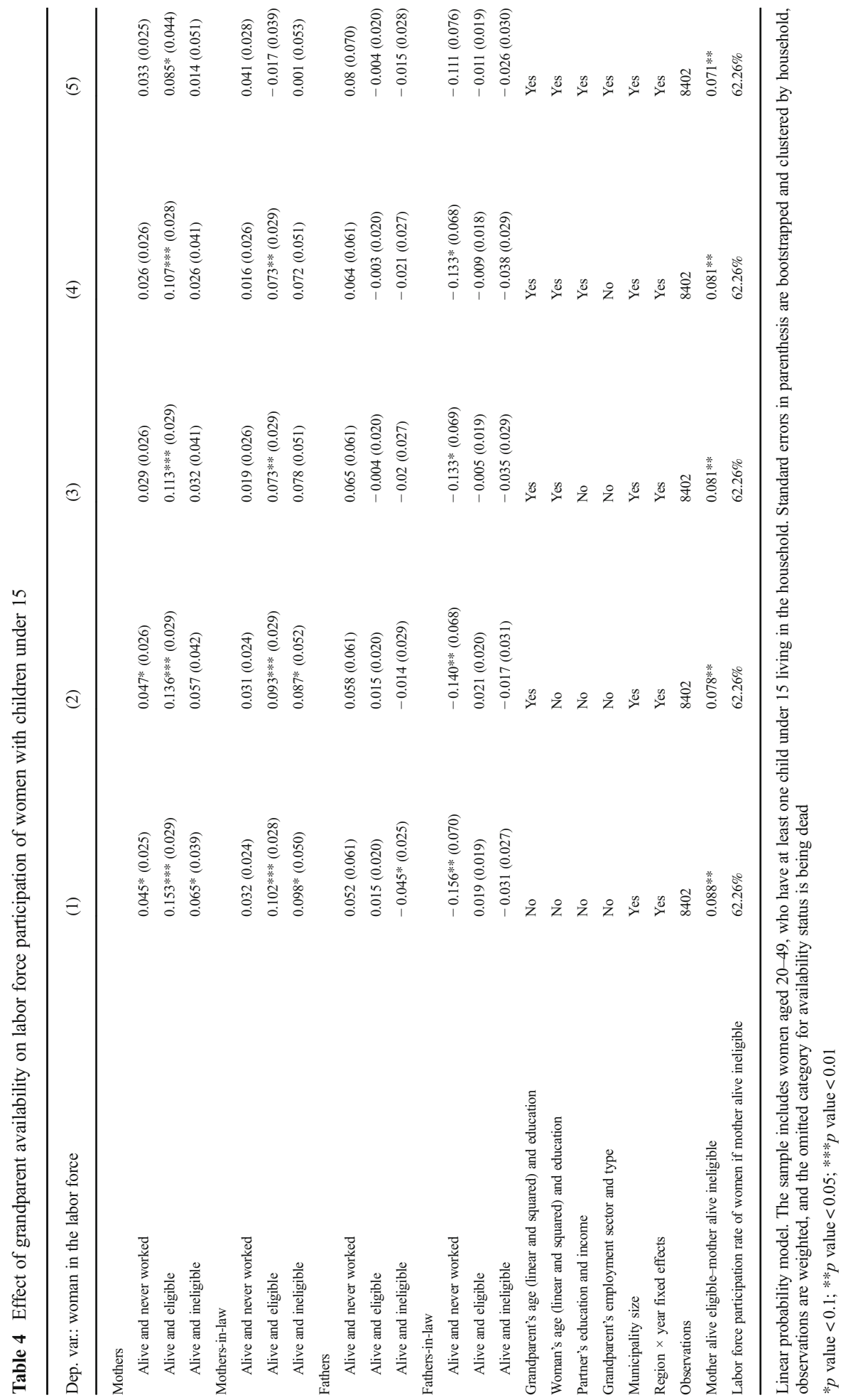


partner's education and income, both of which may affect female LFP. Our key result is consistent throughout all specifications: having a mother who is eligible for a state pension has a positive and strongly statistically significant effect on the probability of labor force participation for a 20- to 49-year-old woman who is mother to a resident child under 15 . The magnitude of the effects implied by the estimates in column (4) is sizable: having a pension-eligible mother implies that her daughter is 10.7 percentage points more likely to participate in the labor force than women whose mother has died, and 8.1 percentage points more likely than those whose mother is currently pension ineligible. ${ }^{18}$

The models used in columns (1)-(4) of Table 4 identify the effect of grandparental retirement eligibility by simultaneously exploiting within-year and between-year variation across individuals. Because grandparental eligibility is imputed based on observable characteristics, some of which are excluded from the LFP equation (i.e., employment sector and type), one possible criticism is that these characteristics may also have a direct effect on maternal employment. Hence, in column (5), we add in dummies for public sector employment and self-employment, allowing us to compare the effect on maternal employment of having grandparents with exactly the same observable characteristics but different pension eligibility. Because grandparental pension eligibility as defined in Section 5 is a nonlinear function of these characteristics, even in this saturated model, we still exploit some cross-sectional variation across individuals in grandparental availability. Nevertheless, most identification is achieved through variation in pension eligibility rules over time resulting from the pension reforms described in Section 3. This claim is verified by Fig. 2, which reports the $R$-squared of yearspecific regressions of each grandparent's pension eligibility status on its determinants. The $R$-squared is very high in all years, and it increases over time as pension eligibility becomes increasingly linked to years of contribution, from about 0.75 in 1993 to 0.95 in the 2000s. Thus, after 2000, almost all variation in eligibility status comes from pension reforms.

Even in the saturated model in column (5), the difference between the coefficients on "mother alive and ineligible" and "mother alive and eligible" amounts to 7.1 percentage points (statistically significant at the 5\% level), an $11 \%$ increase in probability relative to women with ineligible mothers. Moreover, our column (5) estimates show no statistically significant effect of either maternal grandfathers or paternal grandparents on maternal LFP. It is also interesting to note that the coefficients of mother-in-law eligible and mother-in-law ineligible in column (4) are very similar, suggesting a LFP premium that is likely to be related to the mother-in-law's LFP status rather than to her pension eligibility status, an observation confirmed by the drop in both coefficients in column (5) when grandparental employment characteristics are included. In fact, this latter completely absorbs the effect of paternal grandmothers' current or past employment status. ${ }^{19}$ It is worth noting that because

\footnotetext{
${ }_{18}$ The latter effect is measured based on $\beta_{2}-\beta_{3}$, which is reported at the bottom of each column. A test for the hypothesis that $\beta_{2}=\beta_{3}$ rejects the null with a $p$ value of 0.016 .

${ }^{19}$ Even in the presence of unobserved characteristics that are correlated with grandparental employment sector or type, we still consider the contrast $\beta_{2}^{k}-\beta_{3}^{k}$ to be a valid estimate of the effect of having pension-eligible grandparents, because these characteristics are similar across both eligible and ineligible grandparents working in the same employment sector and type. Moreover, later in this section, we also report regression results using definitions of retirement eligibility that are not based on grandparental labor market characteristics.
} 


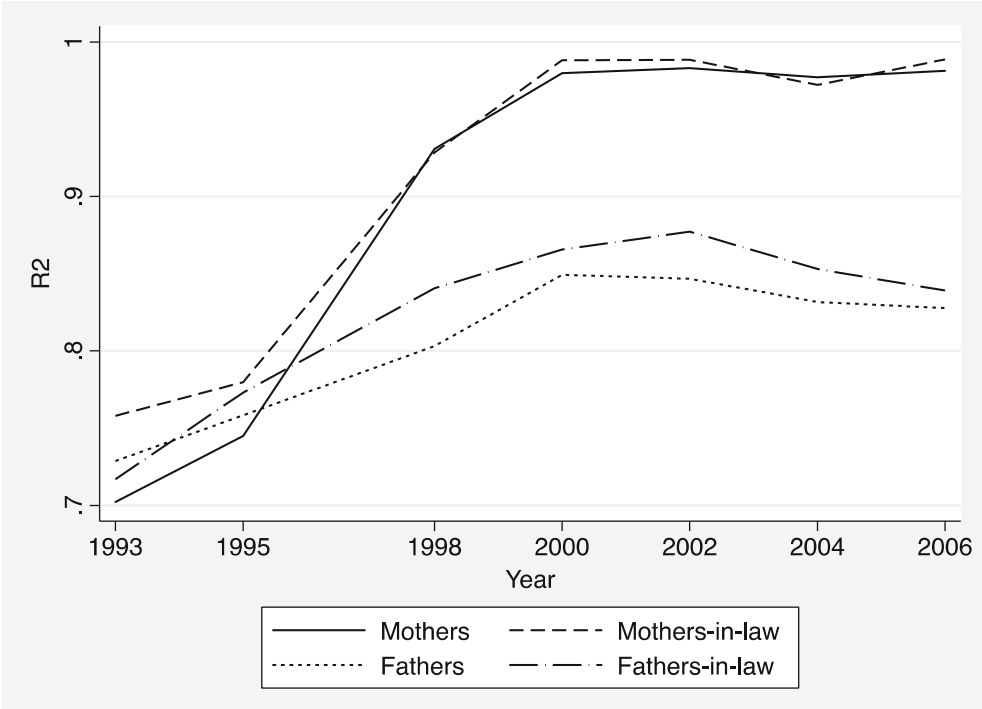

Fig. $2 R$-squared of year-specific regressions of each grandparent's eligibility status on its determinants. Note. The figure reports the $R$-squared of year-specific regressions of dichotomous indicators for each grandparent's pension eligibility status (eligible or not) on their age, and dummies for educational attainment, public sector employment, self-employment, and region of residence

there might be concerns that some of the grandparents' characteristics (namely grandparents' sector and type of job) may be endogenous with respect to mothers' LFP, the fact that the results are largely insensitive to the exclusion (column 4) of such control variables is quite reassuring.

We report in Appendix 2 the results of a number of additional regressions that we have estimated to check the robustness and sensitivity of our main findings. Specifically, we have replaced the dependent variable with, alternatively, employment status, weekly working hours, hourly wages, annual earnings; used alternative definitions of pension eligibility; and accounted for self-selection into motherhood with a Heckman sample selection model. All these additional checks strengthen the results of our analysis. $^{20}$

\subsection{Insights on the causal pathway}

Until now, we have shown that women whose mothers are retirement eligible are significantly more likely to participate in the labor market, an effect that does not

\footnotetext{
${ }^{20}$ In SHIW, each of the spouses provides information about his/her parents. Thus, information about paternal grandparents is not available for single women (i.e., single, separated, divorced, widowed). For this reason, and given that they represent less than $5 \%$ of our sample of women with young children, we prefer to report in the text the estimates on the sample of coupled women. However, we also estimated a modified model in which single mothers are included and all the characteristics of paternal grandparents are excluded from the model, and a model in which single mothers are included and all characteristics of paternal grandparents for single mothers' households are set to zero and interacted with a dummy variable identifying single mothers' households. The difference in LFP between coupled women with and without eligible maternal grandmothers are 6.8 p.p. and 7.3 p.p. in the first and second model, respectively, while in the latter, the same difference cannot be meaningfully estimated for single mothers due to small cell sizes.
} 
hold true for the eligibility of their mothers-in-law. We therefore wonder whether grandparental (potential) availability for childcare is a plausible explanation for this finding. If so, we would expect to find evidence that maternal grandparents (grandmothers) are more likely to provide childcare than paternal grandparents (grandmothers). Extant research supports this view: a greater investment in childcare by maternal grandmothers is a very robust pattern in the sociological, psychological, and evolutionary literature (Coall et al. 2014), one recorded for several countries, including the UK, the USA, Australia, Italy, and Norway (see Whelan 2013; Arpino et al. 2014).

We further check the plausibility of the childcare explanation in several interrelated ways. First, we reestimate Eq. (1) for a sample of female household heads or their partners, again in the 20-49 age range, who are not mothers to any cohabiting children under the age of 15 . For these women, the potential availability of maternal or paternal grandparents for childcare should have no effect on LFP. We report the results for this alternative sample in column (2) of Table 5 with a focus on the most complete specification (equivalent to that in column (5) of Table 4, whose results we repeat for convenience in column (1) of Table 5). These outcomes offer further support for our interpretation of the effects: for women who have no cohabiting children under 15 , there is no indication of a positive effect of the availability of maternal or paternal grandparents on LFP.

We then perform an even more informative validation test for our proposed explanation by estimating Eq. (1) on the subsample of male partners in the estimation sample. Because men are typically less involved in childcare activities ${ }^{21}$ (especially in a Southern European country like Italy), we expect no positive effect of grandparental availability on their LFP unless this availability affects labor market behavior through a channel other than childcare. These results, reported in column (3) of Table 5, indicate that maternal grandparental pension eligibility has no effect on these men's LFP.

A further test for the plausibility of the childcare channel as the main driver of our results relies on the fact that the childcare burden may be especially high during the child's earliest years, so it is then that family childcare support may be most important in determining maternal LFP. If the availability of childcare by a grandmother is driving our results, then the younger her daughter's children, the stronger the effect of the grandmother's pension eligibility should become. Hence, in the last two columns of Table 5, we restrict our sample to women who have children under the age of 11 (column (4)) and under the age of 6 (column (5)). As expected, the estimated effect of a grandmother's pension eligibility increases from a baseline of 0.085 for women with children up to 14 to 0.104 and 0.203 for women whose children are under 11 and under 6 (compulsory school entry age), respectively. These estimates imply that women whose children are under 11 and whose mothers are pension eligible are $11 \%$ (6.5 percentage points) more likely to participate in the labor force than women whose children are in the same age range but whose mother is not yet pension eligible. The same difference increases to $25 \%$ (14.8 percentage points) for women whose children are under 6 , a substantially larger effect than the

\footnotetext{
$\overline{{ }^{21} \text { See, for example, OECD (2001) }}$ and Bloemen et al. (2010).
} 
reduced form effect reported in AFVF (2015) in the sample of women with young children.

A distinctive feature of SHIW data, compared to the FSSS data used in a previous work for Italy (see Section 2), is that it provides information on monetary and house transfers received by a woman or her partner from parents and in-laws on monetary transfers from relatives and friends and on home ownership. This provision allows us to sterilize some potential confounders of the effect of grandparent-provided childcare by including additional regressors aimed at capturing potentially concomitant effects of grandparental retirement eligibility in Eq. (1) (e.g., those mediated by wealth effects). Table 6 thus includes monetary transfers and alternative dummy variables for the following: (i) being owner of the dwelling (vs. rent or free use), which controls for a wealth effect; ii) having received the dwelling as a gift, which controls for any additional effect of severance payments received upon retirement in terms of wealth transfer from grandparents; and (iii) having received the dwelling as an inheritance or gift or being able to use it for free, which controls for any additional financial resources that a household may devote to formal or external childcare. Although these control variables may be potential mediating factors ("bad controls," i.e., potentially affected by grandparent retirement eligibility), this is exactly the reason for their inclusion: to purge out the coefficient on retirement eligibility from the potential mediating factor represented by money and wealth transfers. The three variables are highly correlated, and as shown in columns (1)-(3), the corresponding models exhibit virtually no differences from the baseline model (reported in column (1)). This finding is reassuring evidence of no correlation between retirement eligibility and wealth or monetary transfers, at least as far as these can be measured using the SHIW variables as proxies.

\subsection{Heterogeneous effects}

We investigate potential heterogeneity in the grandparental eligibility effect based on two factors: women's educational levels and the potential supply of external childcare. Because less educated women generally command lower wages in the labor market, their LFP and employment decisions are more sensitive to the availability of low-cost, flexible grandparent-provided childcare than those of highly educated women, who may have access to external childcare (Hofferth and Wissoker 1992; Powell 2002). To check this prediction, in column (2) of Table 7, we estimate a saturated model (reported for convenience in column (1)) that additionally includes the interactions between maternal grandmother's eligibility and the educational attainment of the women in our sample of mothers with cohabiting children. We define as highly educated those women who have completed upper secondary education or more, and as less educated, those who have completed lower secondary education or less. ${ }^{22}$ Less educated women with pension-eligible mothers are 9.7 percentage points more likely to participate in the labor force than their counterparts with ineligible mothers, a difference that is significant at the $10 \%$ level.

\footnotetext{
${ }^{22}$ Our definitions are motivated by the fact that in Italy (unlike in the USA), tertiary educational achievement is very low. Nevertheless, the results remain robust to defining only women with a university degree as highly educated.
} 


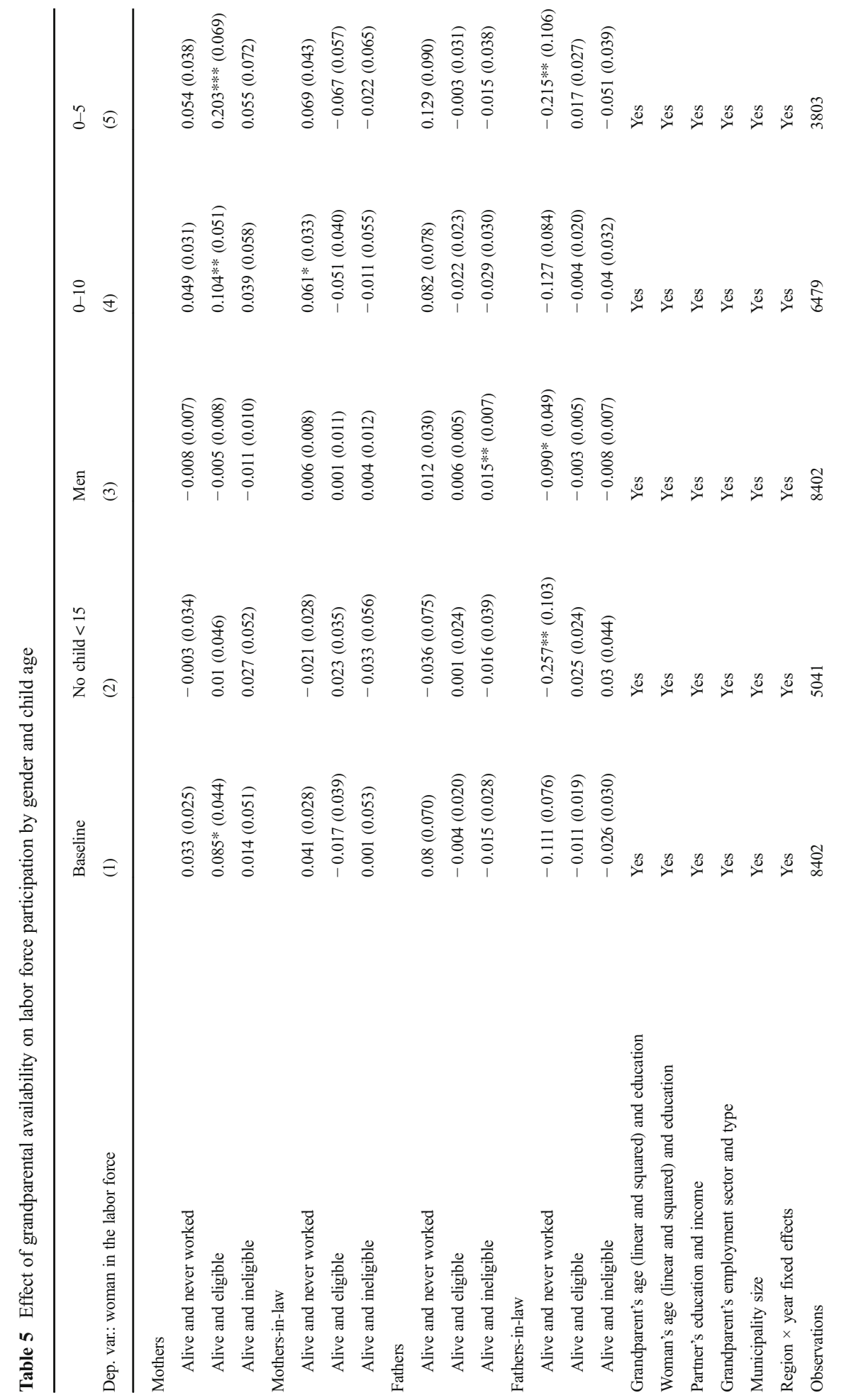




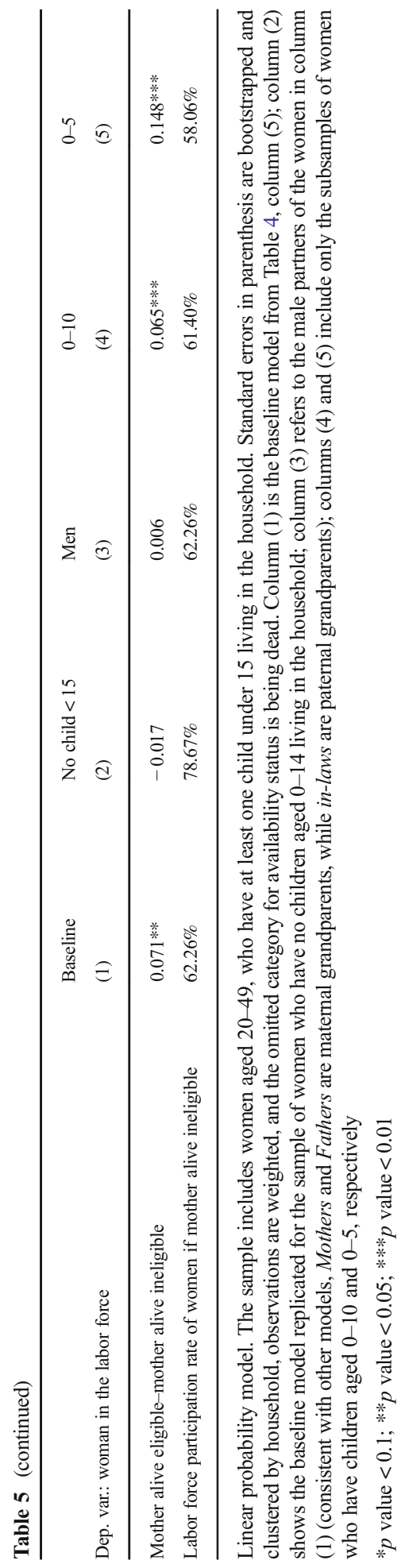




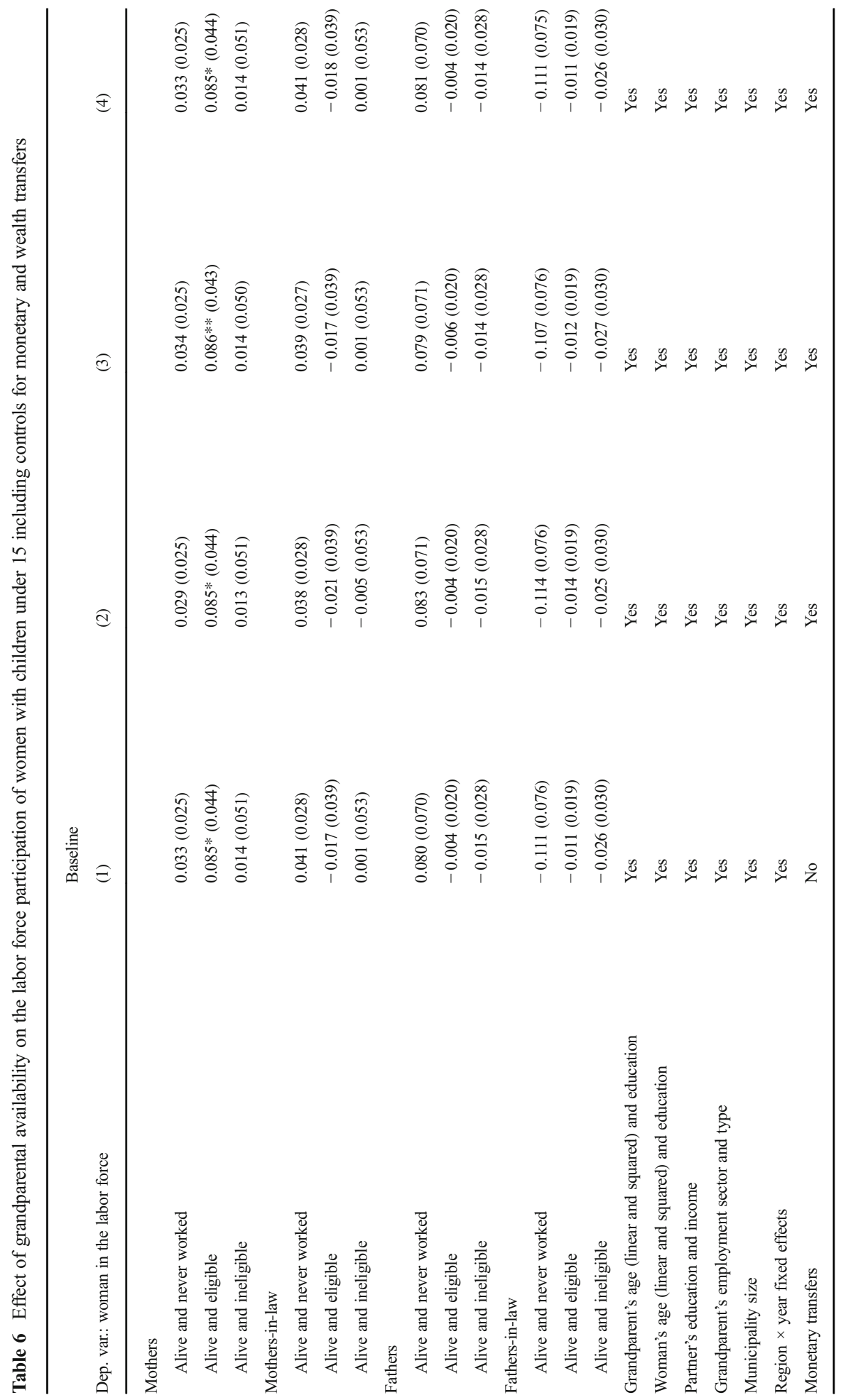




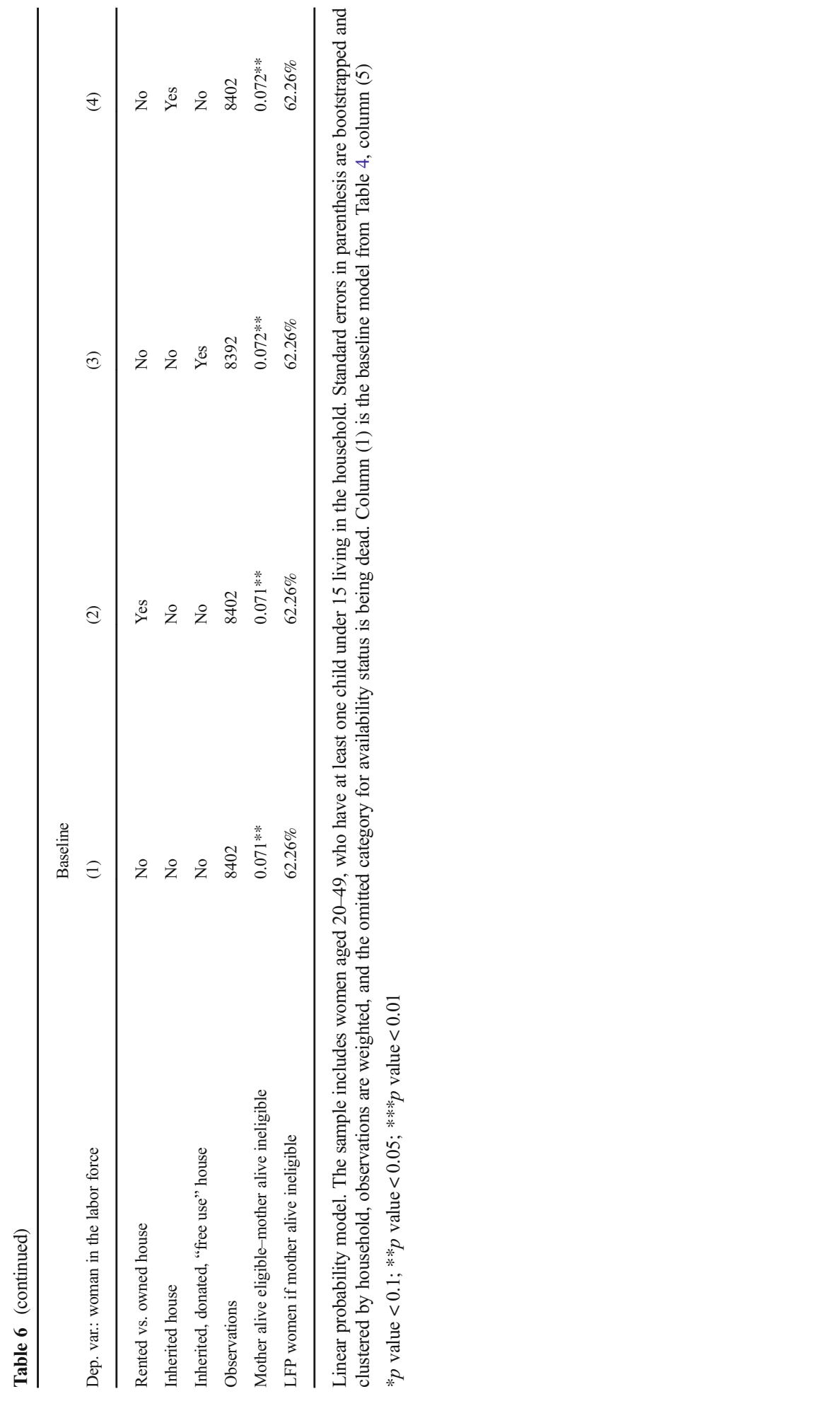




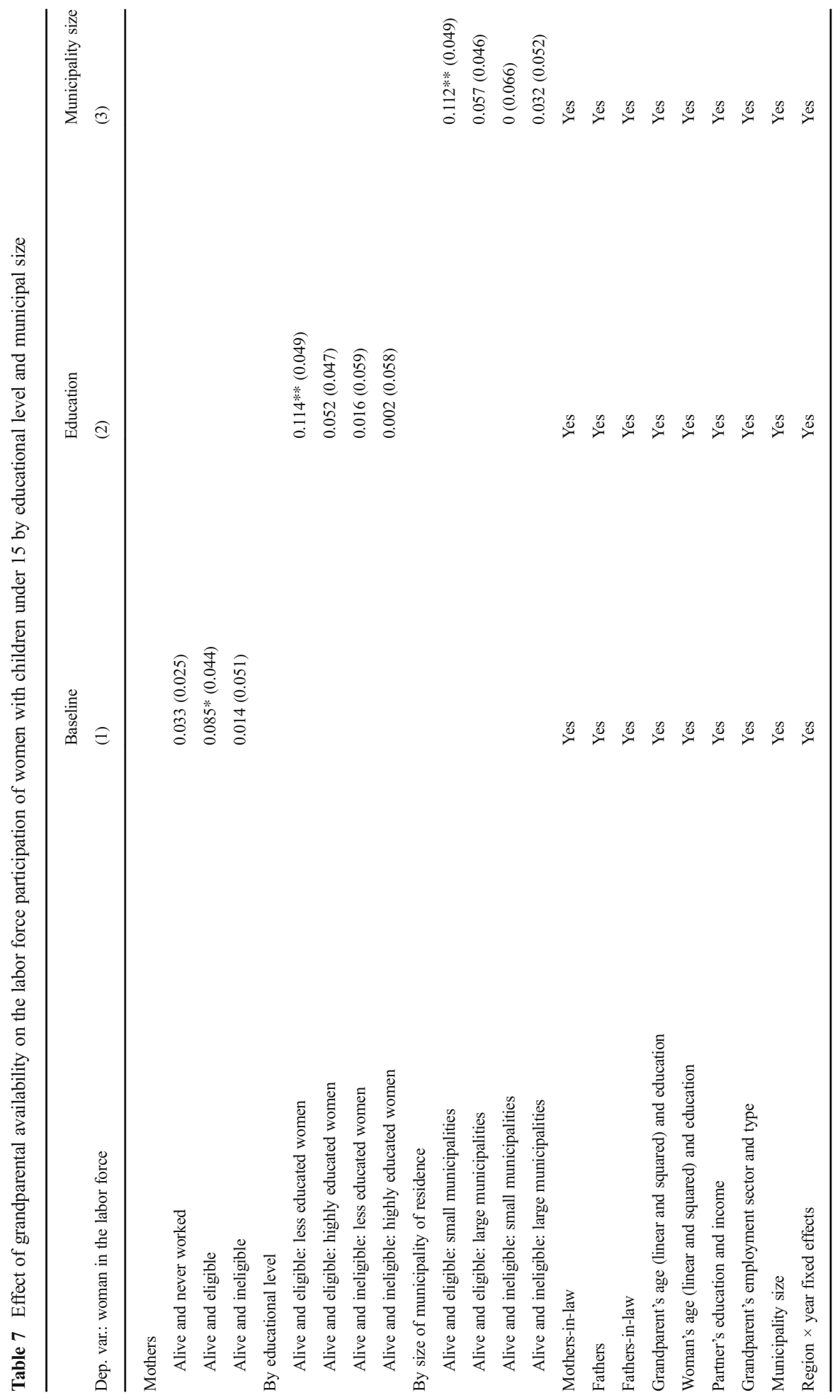




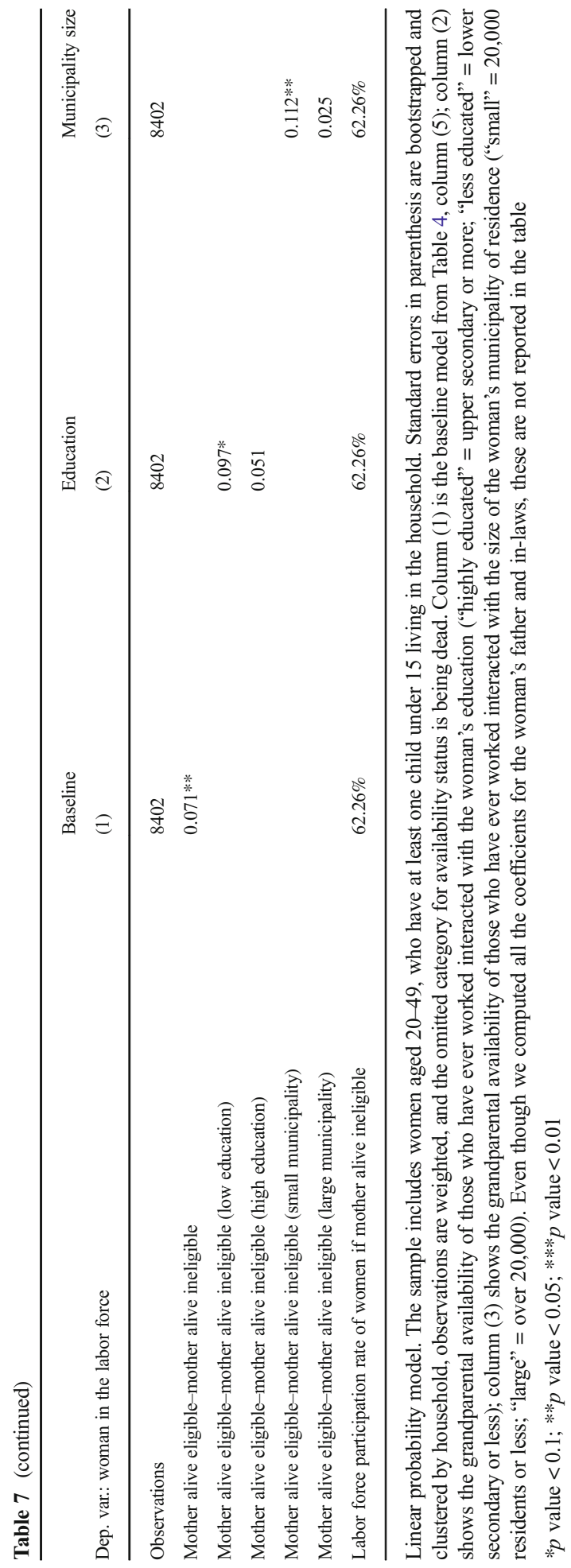


In contrast, the effect for highly educated women, albeit positive, is about 5 percentage points smaller and statistically insignificant.

Because external childcare could be a substitute for grandparent-provided childcare, we expect the effect of grandparental eligibility to be larger when women have access to fewer childcare alternatives. Since public and private formal childcare is likely to be more abundant in larger municipalities, in column (3) of Table 7, we report the estimates from a model that interacts grandparental eligibility with the size of the municipality of residence. The results are consistent with theoretical expectations. In smaller municipalities (20,000 inhabitants or less), the eligible-ineligible grandmother difference amounts to 11.2 percentage points, while in larger municipalities (over 20,000 inhabitants), the difference is much smaller ( 2.5 percentage points) and statistically insignificant. ${ }^{23}$ Since geographical mobility of younger individuals is more frequent from smaller to larger municipalities, another possible explanation of this finding is that in the former women are more likely not to have migrated and reside close to their parents or parents-in-law, who could then provide childcare more easily.

\section{Discussion}

Our finding that women whose mothers are unavailable for childcare suffer a nonnegligible LFP penalty relative to those who can potentially count on such informal assistance throws light on the unintended consequences of pension reforms on maternal labor force participation. In particular, such reforms are likely to penalize women whose mothers become unavailable because of a higher retirement age or stricter retirement requirements. On the other hand, it may also be useful to assess the aggregate effect of pension reforms on the average LFP of all women with children aged 0-14, an effect specific to this demographic group and not to female LFP overall. Overall female LFP may in fact increase if a higher retirement age translates into longer retention of women in the work force. What is likely to change is the distribution of LFP across different generations of women and between women with and without children.

To throw light on this issue, we carry out back-of-the-envelope computations of the average LFP in our sample under different retirement rule scenarios while keeping the sample characteristics fixed. More specifically, we use two scenarios: a pre-Amato scenario and a Dini scenario, in which either the rules predating the Amato reform or the Dini rules (see Table 1) are assumed to be in place for the whole period. After first redefining maternal grandmother eligibility based on these different rule sets, we recompute the average predicted LFP probabilities from our preferred specification for the estimation sample. ${ }^{24}$ The results of this exercise are graphed in Fig. 3. Subfigure

\footnotetext{
${ }^{23}$ This result, however, is only suggestive and should be interpreted with caution. First, detailed data on childcare availability are only available for recent years; for example, ISTAT only provides regional indicators on public childcare since 2004. Second, the supply of public childcare is likely to be endogenous and mainly demand driven. Hence, using data from 2004, we regress on a regional level the logarithm of the percentage of municipalities that implemented childcare services on the logarithm of the percentage of municipalities with over 20,000 inhabitants (controlling for macroarea indicators) and obtain an elasticity of $0.49(t=1.98)$. In the absence of better data, we take this result as suggestive of childcare services being more abundant in larger municipalities.

${ }^{24}$ At the aggregate level, these average predicted probabilities can be interpreted as average labor force participation rates.
} 

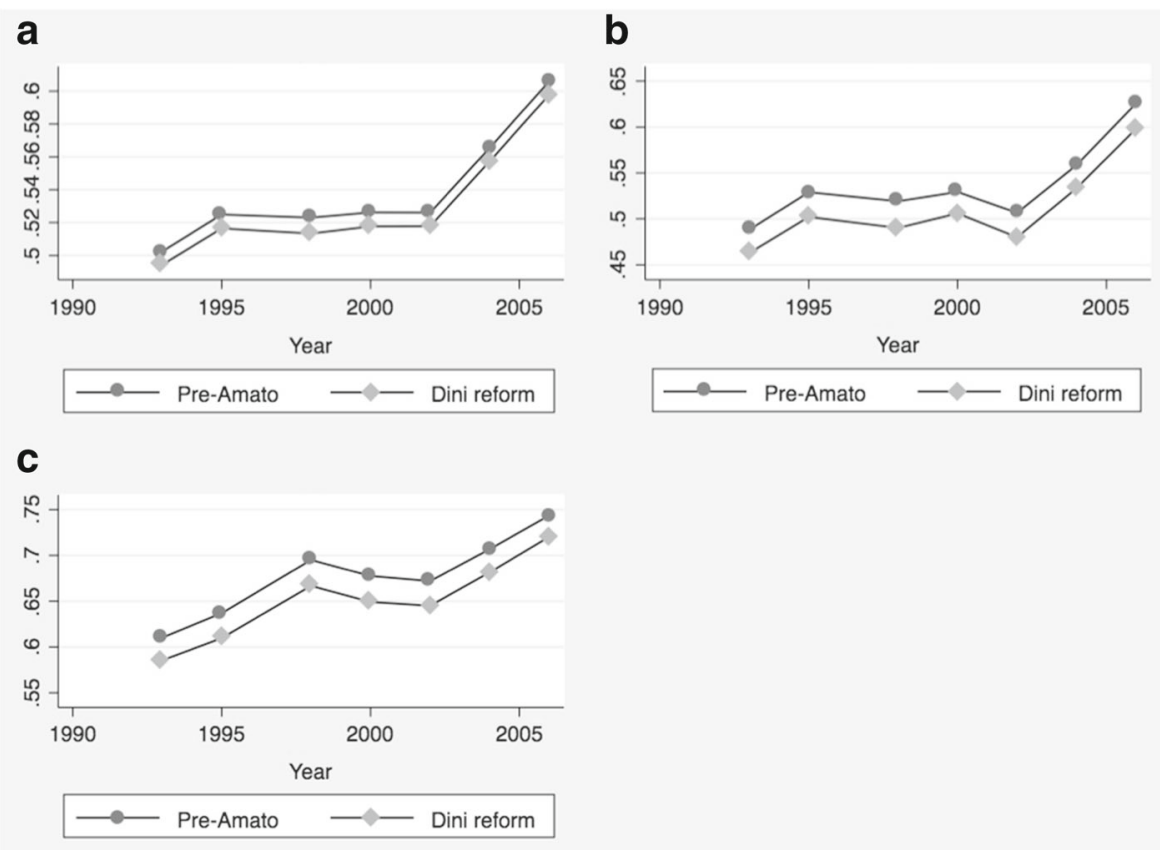

Fig. 3 Simulated labor force participation rates in the sample of women with children aged 0-14 (a) and 0-5 (b), and whose mother participated in the labor force (c). Note. The figure reports the labor force participation rates of different samples of women computed under different sets of rules on pension eligibility for their mothers. Specifically, the darker line with circles is drawn under the assumption that in all years the eligibility rules are those that were in place until 1992 (i.e., before the Amato reform), whereas the lighter line with squares is drawn under the assumption that in all years the more restrictive rules set by the 1995 Dini reform apply to everyone. The samples consist of all women with children aged 0-14 in subfigure a, all women with children aged $0-5$ in subfigure $\mathbf{b}$, and all women with children aged $0-14$, whose mothers participated in the labor force in subfigure c

(a) shows only a small impact of the retirement rules on average LFP, with year differences ranging between 0.80 (1993) and 0.97 (1998) percentage points (see Appendix 3). These differences correspond to about a $1.7 \%$ decline in the labor force participation of mothers. Nevertheless, it must be kept in mind that the main drivers of the average LFP differences between the two scenarios are the differences in share of pension-eligible grandmothers produced by the retirement rules. These latter depend in turn on the demographic characteristics of our estimation sample. For example, high maternal age at first birth is likely to reduce the reform's impact on female LFP in that most women will then have mothers who are old enough to be retirement eligible no matter what rules we consider in our simulations. Subfigure (b) then reports the aggregate effect (computed in the same way) on mothers of preschool children (0-5), for whom, consistent with the results in Table 4, column (5), the interscenario differences increase. We now observe differences between 2.3 (2000) and 2.9 (1998) percentage points, corresponding to $\mathrm{a}-4$ and $-5.5 \%$ decrease in maternal LFP. Another potential determinant of the pension reforms' low impact in the sample of all mothers (i.e., with children 0-14) may be that a substantial proportion of maternal grandmothers have never participated in the labor market and so are unaffected by the retirement rule changes. Thus, in subfigure (c), which 
reports the same two scenarios but with average LFP predicted only for women whose mothers have worked, we observe a much larger gap: the Dini reform has a negative effect on the daughters' LFP, which peaks in 2000 and amounts to a $4.2 \%$ reduction relative to the actual baseline LFP of $67.7 \%$.

\section{Concluding remarks}

In Southern European countries such as Italy, which are characterized by very low provision of public childcare, grandparents offer women an important source of informal childcare, which helps them reconcile family and working life. In this paper, therefore, we seek to quantify the effect of such grandparental availability on maternal LFP. We focus on Italy for two reasons: First, its female employment rates are among the lowest in Europe, making it important to identify which factors are hindering the entry of more women into the workforce. Second, the changes in pension eligibility requirements introduced by Italy's three recent major pension reforms provide exogenous variation in grandparental availability.

Exploiting this exogenous variation, we estimate that mothers of children under 15 whose own mothers are retirement eligible have a 7.1 percentage points higher probability of participating in the labor force $(+11 \%)$ than those whose mothers are ineligible. We interpret this intention-to-treat effect to mean that the potential availability of maternal grandmothers for childcare increases their daughters' LFP, a conclusion supported by several robustness checks. In fact, we find no such effects for either women with no children under 15 or men, and as could be expected, the magnitude of the effects is larger for women with very young children whose childcare needs are most intensive. These findings remain robust even to controlling for parental downstream transfers, considering female employment instead of LFP and addressing potential selection issues into motherhood. We also show that when fully enforced, the pension reforms imply a $1-1.5 \%$ yearly reduction on the LFP rates of women with children aged $0-14$ and a $5.5 \%$ yearly reduction for those with children aged 0 5. Taken together, these results indicate that pension reforms that raise the retirement age or tighten the requirements for seniority pensions, if not coupled with adequate investments in public childcare, may have unintended negative consequences for the employment probabilities of females of childbearing age by robbing households of an important source of flexible, low-cost childcare.

Acknowledgements This version benefited from comments received from two anonymous reviewers and at the 28th EALE Conference (Ghent); the 30th Annual Conference of the European Society for Population Economics (ESPE, Berlin); the 30th Annual Conference of the Italian Association of Labour Economists (AIEL, Cagliari); the ECSR, Collegio Carlo Alberto, and NASP Joint Spring School on "The quantitative analysis of ageing and its relation to social inequality"; the HALM Workshop "Household Economics in an Ageing Society" (Catholic University of Milan); Marche Polytechnic University; the University of Siena; and the University of Milan. The information and views set out in this paper are those of the authors and do not reflect the official opinion of the European Union. Neither the European Union institutions and bodies nor any person acting on their behalf may be held responsible for the use which may be made of the information contained therein. The usual disclaimers apply.

\section{Compliance with ethical standards}

Conflict of interest The authors declare that they have no conflict of interest. 


\section{Appendix 1}

Table 8 Regression for predicted years of contribution

Dep. var.: actual years of contribution

Male

Age

Education: upper secondary and vocational

Education: tertiary

Sector: others

Adjusted $R$-squared

Standard errors in parenthesis

OLS. The sample includes all individuals in the SHIW sample $* p$ value $<0.1 ; * * p$ value $<0.05 ; * * * p$ value $<0.01$

\section{Appendix 2. Robustness checks and further evidence}

We report in this appendix a number of additional analyses that we have performed to check the robustness and sensitivity of our results. Specifically, we have replaced the dependent variable with, alternatively, employment status, weekly working hours, hourly wages, annual earnings; used alternative definitions of pension eligibility; and 
accounted for self-selection into motherhood with a Heckman sample selection model. All these additional checks strengthen the results of our analysis.

Employment. In Table 9, we report the same models estimated in Table 4 but using as our dependent variable a dichotomous indicator equal to 1 if a woman is employed and 0 otherwise. Results are very close to those using LFP: in the saturated model (column (5) of Table 9), among the eight grandparent eligibility variables, only the coefficient on maternal grandmother eligibility is statistically significant at the 5\% level. Women with pensioneligible mothers have an 8.5 and 7.7 percentage point higher employment probability, respectively, than women whose mothers are dead or pension ineligible. The corresponding effects on LFP are 8.5 percentage points and 7.1 percentage points, respectively (column (5) of Table 4). The fact that the LFP and employment results are practically indistinguishable strongly suggests that the pension eligibility status of maternal grandmothers does indeed capture the effect of their childcare provision. In fact, we expect no significant effect on unemployed mothers, who can personally take care of their children.

Intensive margins. The availability of informal childcare may affect not only LFP (or employment) probability but also the intensive margin of labor supply; that is, the number of hours worked, or even women's productivity, reflected in wages and earnings. Grandparents may, for instance, take care of children when they are ill, reducing the number of maternal absences from work in the short run and possibly even improving the latter's career prospects in the long run. To gain an approximate idea of the grandparent availability effect on weekly working hours, hourly wages, and annual earnings, we use the saturated model to estimate logarithmic regressions on the sample of working mothers. The estimated effects of maternal grandmother availability are $0.022,0.045$, and 0.075 on hours, wages, and earnings, respectively, none of which are statistically significant at conventional levels (results are available upon request). Thus, overall, there is no compelling evidence that grandmother availability for childcare affects the intensive margin of labor supply or productivity. Grandmothers simply seem to help working women to overcome their first important obstacle after having children - remaining attached to the labor force.

Alternative definitions of pension eligibility. We have stated earlier in this paper that considering seniority-based pension rules in addition to age-based pension rules increases the precision of our measure of grandparental eligibility and potential availability for childcare. To support this claim, here we redefine eligibility based purely on age and then reestimate the saturated model. The results, reported in column (2) of Table 10, are qualitatively similar to (albeit less precisely estimated than) our baseline findings (column (1)): a 0.043 difference in LFP between women with and without eligible mothers, which is in line with that reported in the reduced form estimates of AFVF (2015). This difference is, however, not statistically significant at conventional levels, presumably because of the noisier imputation of eligibility status, which does not consider the requirements for seniority pensions.

Finally, in column (2) of Table 11, we follow Aparicio-Fenoll and VidalFernandez (2015) by imputing eligibility only on age and omitting controls for grandparental education and employment sector and type. Although the coefficient on grandparental eligibility increases and is significant at $5 \%$, the contrast between pension-eligible and nonpension-eligible maternal grandmothers further reduces in size $(0.037)$ and loses statistical significance. This outcome again underscores the importance of exploiting seniority pension rules in defining retirement eligibility. 
Sample selection issues. The final concern that we address is related to our initial sample selection. Because we focus on the effect of grandparental childcare availability on maternal labor force participation, our analysis is conditional on women having children aged 0-14 living in the household. Yet this condition begs the question of whether this population of interest actually constitutes a random sample of women with respect to unobservable characteristics that potentially affect labor market behavior. For example, if we were also to include childless women entering motherhood, would the effect of grandparental eligibility be larger or smaller than that reported? To provide a tentative answer, we estimate a Heckman selection model using the main equation for LFP and a selection equation for the presence of children aged $0-14$ in the household. Although the model is formally identified even without an exclusion restriction (Puhani 2000), we propose an economic identification that uses as "instrument" a proxy for the woman's spouse being an only child; that is, the number (from the SHIW) of noncohabiting siblings still alive for each individual in a couple. This number is likely to be a good proxy for onlychild status because mortality is still low in the age groups considered and sibling cohabitation after forming families and having children is very rare.

The underlying rationale for using this instrument is that being raised as an only child may affect each spouse's fertility preferences, which are likely to shape the couple's actual fertility. We assume that conditional on the large set of observables included in our models (such as women's, grandparents', and partners' characteristics, including the latter's level of education and income), the spouse's only-child status is exogenous with respect to the woman's labor market attachment. We consider only the spousal status because previous studies show that maternal grandparents are the most likely to provide childcare, so the women's only-child status may violate the exclusion restriction assumption if siblings create higher competition for the maternal grandmother's childcare. We also expect this focus to break any potential link between a woman's fertility, her mother's fertility, and the woman's labor market preferences, which may be correlated across generations because of unobservable attributes. ${ }^{25}$

Table 11 reports the results of the Heckman selection model. Column (1) shows the coefficients of the selection equation, and column (2) those of the main equation. The spouse's only-child status significantly predicts the presence of young children in the household: only-child men are 4.7 ( $p$ value $=0.028$ ) percentage points less likely to have cohabiting young children. Interestingly, women with eligible mothers have a 3.5. percentage points higher probability of having young cohabiting children than those with ineligible mothers, a finding consistent with the effect reported by Battistin et al. (2015) on fertility, although in our case, the estimate is not statistically significant. This outcome may be due to the different dependent variables used in the two studies. For our study, the relevant selection is on the presence of young children in the household (see also Battistin et al. 2015 , for a comprehensive analysis of the effect of grandparental pension eligibility on fertility). All effects for the selection equation are computed as average marginal effects. The coefficient on the inverse Mill's ratio is positive, but conditioning on a large set of

\footnotetext{
$\overline{{ }^{25}}$ The estimates in this section must be nonetheless interpreted with caution because some residual endogeneity may remain if the spouse's only-child status is affected by unobservable variables that also determine her partner's LFP. To the best of our knowledge, the existing literature focuses mainly on motherson or mother-daughter intergenerational fertility correlations (e.g., Kolk 2014; Cools and Kaldager Hart 2016), while much less is known about the relation between a woman's fertility choices and her partner's family size.
} 
controls is not statistically significant at conventional levels. Column (2) also shows that eligible grandmothers increase LFP by an estimated 7.9 percentage points with respect to noneligible grandmothers. This effect is practically the same as that estimated in the model that does not account for selection. Although we do not consider this evidence as definitive proof of the absence of a sample selection bias, which would allow us to generalize our estimated effects to childless women if they were mothers, it is nonetheless indicative that the bias, if any, is unlikely to be severe.

Table 9 Effect of grandparental availability on the employment of women with children under 15

\begin{tabular}{|c|c|c|c|c|c|}
\hline $\begin{array}{l}\text { Dep. var: woman } \\
\text { employment }\end{array}$ & (1) & (2) & (3) & (4) & $(5)$ \\
\hline \multicolumn{6}{|l|}{ Mothers } \\
\hline Alive and never worked & $0.038(0.025)$ & $0.04(0.026)$ & $0.022(0.026)$ & $0.019(0.025)$ & $0.026(0.025)$ \\
\hline Alive and eligible & $0.151 * * *(0.029)$ & $0.131 * * *(0.029)$ & $0.109 * * *(0.029)$ & $0.103 * * *(0.029)$ & $0.085 *(0.044)$ \\
\hline Alive and ineligible & $0.053(0.038)$ & $0.047(0.041)$ & $0.022(0.040)$ & $0.015(0.039)$ & $0.007(0.049)$ \\
\hline \multicolumn{6}{|l|}{ Mothers-in-law } \\
\hline Alive and never worked & $0.036(0.023)$ & $0.037(0.024)$ & $0.025(0.025)$ & $0.022(0.025)$ & $0.041(0.028)$ \\
\hline Alive and eligible & $0.096^{* * *}(0.028)$ & $0.086^{* * *}(0.029)$ & $0.065 * *(0.029)$ & $0.065 * *(0.029)$ & $-0.003(0.040)$ \\
\hline Alive and ineligible & $0.080 *(0.047)$ & $0.083 *(0.048)$ & $0.073(0.048)$ & $0.067(0.047)$ & $0.016(0.052)$ \\
\hline \multicolumn{6}{|l|}{ Fathers } \\
\hline Alive and never worked & $0.035(0.062)$ & $0.045(0.062)$ & $0.053(0.062)$ & $0.052(0.062)$ & $0.074(0.071)$ \\
\hline Alive and eligible & $0.015(0.021)$ & $0.017(0.021)$ & $-0.002(0.021)$ & $-0.002(0.021)$ & $-0.004(0.021)$ \\
\hline Alive and ineligible & $-0.038(0.026)$ & $0.003(0.030)$ & $-0.003(0.029)$ & $-0.004(0.028)$ & $0.005(0.029)$ \\
\hline \multicolumn{6}{|l|}{ Fathers-in-law } \\
\hline Alive and never worked & $-0.132 *(0.072)$ & $-0.103(0.070)$ & $-0.097(0.071)$ & $-0.098(0.070)$ & $-0.07(0.077)$ \\
\hline Alive and eligible & $0.023(0.020)$ & $0.027(0.020)$ & $0.002(0.019)$ & $-0.003(0.019)$ & $-0.004(0.019)$ \\
\hline Alive and ineligible & $-0.029(0.028)$ & $-0.001(0.032)$ & $-0.02(0.030)$ & $-0.024(0.030)$ & $-0.01(0.030)$ \\
\hline $\begin{array}{l}\text { Grandparent's age (linear and } \\
\text { squared) and education }\end{array}$ & No & Yes & Yes & Yes & Yes \\
\hline $\begin{array}{l}\text { Woman's age (linear and } \\
\text { squared) and education }\end{array}$ & No & No & Yes & Yes & Yes \\
\hline $\begin{array}{l}\text { Partner's education and } \\
\text { income }\end{array}$ & No & No & No & Yes & Yes \\
\hline $\begin{array}{l}\text { Grandparent's employment } \\
\text { sector and type }\end{array}$ & No & No & No & No & Yes \\
\hline Municipality size & Yes & Yes & Yes & Yes & Yes \\
\hline Region $\times$ year fixed effects & Yes & Yes & Yes & Yes & Yes \\
\hline Observations & 8402 & 8402 & 8402 & 8402 & 8402 \\
\hline $\begin{array}{l}\text { Mother alive eligible-mother } \\
\text { alive ineligible }\end{array}$ & $0.098 * * *$ & $0.084 * *$ & $0.087 * * *$ & $0.088^{* * *}$ & $0.077 * *$ \\
\hline $\begin{array}{l}\text { Employment rate of women if } \\
\text { mother alive ineligible }\end{array}$ & $59.25 \%$ & $59.25 \%$ & $59.25 \%$ & $59.25 \%$ & $59.25 \%$ \\
\hline
\end{tabular}

Linear probability model. The sample includes women aged 20-49, who have at least one child under 15 living in the household. Standard errors in parenthesis are bootstrapped and clustered by household, observations are weighted, and the omitted category for availability status is being dead

$* p$ value $<0.1 ; * * p$ value $<0.05 ; * * * p$ value $<0.01$ 
Table 10 Effect of grandparental availability on the labor force participation of women with children under 15 under different imputations of retirement eligibility

Basis for eligibility

Our definition Age only Age only

Dep. var.: woman in the labor force

(1)

(2)

(3)

\section{Mothers}

Alive and never worked

$\begin{array}{lll}0.033(0.025) & 0.035(0.025) & 0.025(0.025) \\ 0.085^{*}(0.044) & 0.065(0.043) & 0.094 * * *(0.029) \\ 0.014(0.051) & 0.022(0.057) & 0.057(0.046)\end{array}$

Alive and eligible

$0.014(0.051) \quad 0.022(0.057)$

0.057 (0.046)

Mothers-in-law

Alive and never worked

$\begin{array}{lll}0.041(0.028) & 0.041(0.028) & 0.020(0.026) \\ -0.017(0.039) & -0.023(0.038) & 0.062 * *(0.029) \\ 0.001(0.053) & 0.094(0.068) & 0.186 * * *(0.065)\end{array}$

Alive and ineligible

$0.001(0.053) \quad 0.094(0.068)$

$0.186 * * *(0.065)$

Fathers

Alive and never worked

$0.08(0.070) \quad 0.088(0.070) \quad 0.069(0.062)$

Alive and eligible

$\begin{array}{lll}-0.004(0.020) & -0.005(0.020) & -0.004(0.020)\end{array}$

Alive and ineligible

$-0.015(0.028) \quad-0.037(0.035) \quad-0.031(0.036)$

Fathers-in-law

Alive and never worked

Alive and eligible

Alive and ineligible

Grandparent's age (linear and squared) and education

Woman's age (linear and squared) and education

Partner's education and income

$\begin{array}{lll}-0.111(0.076) & -0.103(0.075) & -0.131 *(0.068) \\ -0.011(0.019) & -0.010(0.018) & -0.009(0.018) \\ -0.026(0.030) & -0.053(0.052) & -0.062(0.054) \\ \text { Yes } & \text { Yes } & \text { Only age } \\ \text { Yes } & \text { Yes } & \text { Yes } \\ \text { Yes } & \text { Yes } & \text { Yes } \\ \text { Yes } & \text { Yes } & \text { No } \\ \text { Yes } & \text { Yes } & \text { Yes } \\ \text { Yes } & \text { Yes } & \text { Yes } \\ 8402 & 8402 & 8402 \\ 0.071 * * & 0.043 & 0.037 \\ 62.26 \% & 58.76 \% & 58.76 \%\end{array}$

Grandparent's employment sector and type

Municipality size

Region $\times$ year fixed effects

Observations

Mother alive eligible-mother alive ineligible

Labor force participation rate of women if mother alive ineligible

$62.26 \%$

$58.76 \%$

$58.76 \%$

Linear probability model. The sample includes women aged 20-49, who have at least one child under 15 living in the household. Standard errors in parenthesis are bootstrapped only in column (1) and clustered by household, observations are weighted, and the omitted category for availability status is being dead $* p$ value $<0.1 ; * * p$ value $<0.05 ; * * * p$ value $<0.01$ 
Table 11 Effect of grandparental availability on the labor force participation of women with children under 15-Heckman selection model

Dep. var.

Child 0-14 (selection)

LFP

(1)

(2)

Mothers

Alive and never worked

Alive and eligible

Alive and ineligible

Mothers-in-law

Alive and never worked

Alive and eligible

Alive and ineligible

Fathers

Alive and never worked

Alive and eligible

Alive and ineligible

Fathers-in-law

Alive and never worked

Alive and eligible

Alive and ineligible

No. of spouse's noncohabiting siblings alive

Inverse Mill's ratio

Grandparent's age (linear and squared) and education

Woman's age (linear and squared) and education

Partner's education and income

Grandparent's employment sector and type

Municipality size

Region $\times$ year fixed effects

Observations

Mother alive eligible--mother alive ineligible

Labor force participation rate of women if mother alive ineligible

$\begin{array}{ll}0.049(0.075) & 0.034(0.029) \\ 0.150(0.130) & 0.094 * *(0.05) \\ 0.031(0.126) & 0.015(0.053) \\ & \\ 0.027(0.067) & 0.045(0.030) \\ 0.000(0.103) & -0.017(0.043) \\ 0.043(0.135) & 0.006(0.054)\end{array}$

$0.085(0.288)$

$0.094(0.071)$

$0.020(0.052)$

$-0.005(0.030)$

$-0.026(0.097)$

$-0.012(0.029)$

$0.146(0.269)$

$-0.132 *(0.072)$

$0.094(0.054)$

$-0.007(0.027)$

$-0.041(0.100)$

$-0.031(0.031)$

$0.157^{* *}(0.078)$

$0.123(0.338)$

Yes

Yes

Yes Yes

Yes Yes

Yes Yes

Yes Yes

Yes Yes

$13,441 \quad 8402$

$0.035 \quad 0.079 * *$

$\begin{array}{ll}62.49 \% & 59.25 \%\end{array}$

Linear probability model. The sample includes women aged 20-49, who have at least one child under 15 living in the household. Standard errors in parenthesis are bootstrapped only in column (1) and clustered by household, observations are weighted, and the omitted category for availability status is being dead. Column (1) reports the coefficients of the probit selection equation

$* p$ value $<0.1 ; * * p$ value $<0.05 ; * * * p$ value $<0.01$ 


\section{Appendix 3. Predicted labor force participation rates}

Table 12 Predicted labor force participation rates under different scenarios

\begin{tabular}{lllllllllll}
\hline \multicolumn{3}{c}{ Full sample (a) } & \multicolumn{7}{c}{ With children aged 0-5 (b) } & \multicolumn{3}{c}{$\begin{array}{l}\text { With grandmothers who have ever been in } \\
\text { labor force (c) }\end{array}$} \\
Year & Pre-Amato & Dini & Difference & Pre-Amato & Dini & Difference & Pre-Amato & Dini & Difference \\
\hline 1993 & 0.5024 & 0.4944 & 0.0080 & 0.4880 & 0.4627 & 0.0253 & 0.6102 & 0.5854 & 0.0248 \\
1995 & 0.5249 & 0.5164 & 0.0085 & 0.5291 & 0.5020 & 0.0271 & 0.6369 & 0.6097 & 0.0272 \\
1998 & 0.5230 & 0.5133 & 0.0097 & 0.5192 & 0.4900 & 0.0292 & 0.6950 & 0.6668 & 0.0282 \\
2000 & 0.5262 & 0.5177 & 0.0085 & 0.5294 & 0.5060 & 0.0234 & 0.6775 & 0.6491 & 0.0284 \\
2002 & 0.5261 & 0.5178 & 0.0084 & 0.5066 & 0.4799 & 0.0267 & 0.6719 & 0.6451 & 0.0268 \\
2004 & 0.5654 & 0.5572 & 0.0082 & 0.5588 & 0.5336 & 0.0252 & 0.7067 & 0.6815 & 0.0252 \\
2006 & 0.6059 & 0.5978 & 0.0081 & 0.6261 & 0.5986 & 0.0275 & 0.7435 & 0.7202 & 0.0233 \\
\hline
\end{tabular}

The table reports the labor force participation rates of different samples of women computed under different set of rules on pension eligibility for their mothers. The pre-Amato scenario is based on the assumption that in all years the eligibility rules are those that were in place until 1992 (i.e., before the Amato reform). The Dini scenario is based on the assumption that in all years the more restrictive rules set by the 1995 Dini reform apply to everyone. The column "Difference" shows the difference between the two scenarios. The three samples considered consist of all women with children aged 0-14 (a), all women with children aged 0-5 (b), and all women with children aged 0-14, whose mothers participated in the labor force (c). These labor force participation probabilities are plotted in Fig. 3

Open Access This article is distributed under the terms of the Creative Commons Attribution 4.0 International License (http://creativecommons.org/licenses/by/4.0/), which permits unrestricted use, distribution, and reproduction in any medium, provided you give appropriate credit to the original author(s) and the source, provide a link to the Creative Commons license, and indicate if changes were made.

\section{References}

Abendroth AK, van der Lippe T, Maas I (2012) Social support and the working hours of employed mothers in Europe: the relevance of the state, the workplace, and the family. Soc Sci Res 41(3):581-597. https://doi. org/10.1016/j.ssresearch.2011.12.008

Aparicio-Fenoll A, Vidal-Fernandez M (2015) Working women and fertility: the role of grandmothers' labor force participation. CESifo Econ Stud 61(1):123-147. https://doi.org/10.1093/cesifo/ifu030

Ardito, C. 2017. Rising pension age in Italy: employment response and program substitution. LABOR Laboratorio Riccardo Revelli (Centre for Employment Studies) Working Papers No. 155

Arpino B, Pronzato C, Tavares L (2014) The effect of grandparental support on mothers' labor market participation: an instrumental variable approach. Eur J Popul 30(4):369-390. https://doi.org/10.1007 /s10680-014-9319-8

Bailey MJ (2006) More power to the pill: the impact of contraceptive freedom on women's life cycle labor supply. Q J Econ 121(1):289-320

Behaghel L, Blau D (2012) Framing social security reform: behavioral responses to changes in the full retirement age. Am Econ J Econ Pol 4(4):41-67. https://doi.org/10.1257/pol.4.4.41

Battistin E, Brugiavini A, Rettore E, Weber G (2009) The retirement consumption puzzle: evidence from a regression discontinuity approach. Am Econ Rev 99(5):2209-2226. https://doi.org/10.1257/aer.99.5.2209

Battistin E., M. de Nadai, and M. Padula. 2015. Roadblocks on the road to grandma's house: fertility consequences of delayed retirement. Queen Mary, University of London Working Paper No. 748 
Bloemen H, Pasqua S, Stancanelli E (2010) An empirical analysis of the time allocation of Italian couples: are they responsive? Rev Econ Househ 8(3):345-369. https://doi.org/10.1007/s11150-009-9083-4

Bottazzi R, Jappelli T, Padula M (2006) Retirement expectations, pension reforms, and their impact on private wealth accumulation. J Public Econ 90(12):2187-2212. https://doi.org/10.1016/j. jpubeco.2006.03.005

Brugiavini, A., and Peracchi, F. 2012. Health status, welfare programs participation, and labor force activity in Italy, NBER chapters. In: Social security programs and retirement around the world: historical trends in mortality and health, employment, and disability insurance participation, 175-215. National Bureau of Economic Research, Inc. doi: https://doi.org/10.7208 /chicago/9780226921952.003.0005.

Càceres-Delpiano J (2012) Can we still learn something from the relationship between fertility and mother's employment? Evidence from developing countries. Demography 49(1):151-174. https://doi.org/10.1007 /s13524-011-0076-6

Coall DA, Hilbrand S, Hertwig R (2014) Predictors of grandparental investment decisions in contemporary Europe: biological relatedness and beyond. PLoS One 9(1):e84082. https://doi.org/10.1371/journal. pone.0084082

Compton J, Pollak RA (2014) Family proximity, child care, and women's labor force attachment. J Urban Econ 79(C):72-90. https://doi.org/10.1016/j.jue.2013.03.007

Cools S, Kaldager Hart R (2016) The effect of childhood family size on fertility in adulthood: new evidence from IV estimation. Demography 54:23-44. https://doi.org/10.1007/s13524-016-0537-z

Cristia J (2008) The effect of a first child on female labor supply: evidence from women seeking fertility services. J Hum Resour 43(3):487-510

Cruces G, Galiani S (2007) Fertility and female labor supply in Latin America: new causal evidence. Labour Econ 14(3):565-573. https://doi.org/10.1016/j.labeco.2005.10.006

Del Boca D (2002) The effect of child care and part time opportunities on participation and fertility decisions in Italy. J Popul Econ 15(3):549-573. https://doi.org/10.1007/s001480100089

Del Boca D, Sauer RM (2009) Life cycle employment and fertility across institutional environments. Eur Econ Rev 53(3):274-292. https://doi.org/10.1016/j.euroecorev.2008.06.001

Del Boca D, Vuri D (2007) The mismatch between employment and child care in Italy: the impact of rationing. J Popul Econ 20(4):805-832. https://doi.org/10.1007/s00148-006-0126-3

Farre L, Vella F (2013) The intergenerational transmission of gender role attitudes and its implications for female labour force participation. Economica 80(318):219-247. https://doi. org/10.1111/ecca.12008

Gruber, J. and Wise, D. A. 2007. Social security programs and retirement around the world: fiscal implications of reform. NBER Books, National Bureau of Economic Research, Inc. doi: https://doi.org/10.7208 /chicago/9780226310008.001.0001

Hank K, Buber I (2009) Grandparents caring for their grandchildren. J Fam Issues 30(1):53-73. https://doi. org/10.1177/0192513X08322627

Ho C (2015) Grandchild care, intergenerational transfers, and grandparents' labor supply. Rev Econ Househ 13(2):359-384. https://doi.org/10.1007/s11150-013-9221-x

Hofferth SL, Wissoker DA (1992) Price, quality, and income in child care choice. J Hum Resour 27(1):70111. https://doi.org/10.2307/145913

ISTAT (2005) Essere madri in Italia. Anno 2005. In: Famiglia e Società - Statistiche in breve. ISTAT, Rome

Kolk M (2014) Multigenerational transmission of family size in contemporary Sweden. Popul Stud 68(1):111129. https://doi.org/10.1080/00324728.2013.819112

Leibowitz A, Klerman JA, Waite LJ (1992) Employment of new mothers and child care choice: differences by children's age. J Hum Resour 27(1):112-133. https://doi.org/10.2307/145914

Lewbel A (2007) Estimation of average treatment effects with misclassification. Econometrica 75(2):537-551. https://doi.org/10.1111/j.1468-0262.2006.00756.x

Lumsdaine, R. L. and S. J. C. Vermeer. 2014. Retirement timing of women and the role of care responsibilities for grandchildren. NBER Working Papers 20756, National Bureau of Economic Research, Inc.

OECD (2001) Balancing work and family life: helping parents into paid employment. In: Chapter 4 of Employment outlook. OECD Publishing, Paris

OECD (2012) Closing the gender gap: act now. OECD Publishing, Paris

Ogawa N, Ermisch JF (1996) Family structure, home time demands and the employment patterns of Japanese married women. J Labor Econ 14(4):677-702. https://doi.org/10.1086/209827

Posadas J, Vidal-Fernandez M (2013) Grandparents' child care and female labor force participation. IZA J Labor Policy 3(14):1-20 
Powell LM (2002) Joint labor supply and child care choice decisions of married mothers. J Hum Resour 37(1): 106-128. https://doi.org/10.2307/3069605

Pronzato C (2009) Return to work after childbirth: does parental leave matter in Europe? Rev Econ Househ 7(4):341-360. https://doi.org/10.1007/s11150-009-9059-4

Puhani PA (2000) The Heckman correction for sample selection and its critique. J Econ Surv 14(1):53-68. https://doi.org/10.1111/1467-6419.00104

Rupert, P., and G. Zanella. 2014. Grandchildren and their grandparents' labor supply. Working Paper No. 937, Department of Economic Science, University of Bologna

Whelan, S. 2013. Work or care? The labour market activity of grandparents in Australia. University of Sydney, mimeo

Zanella G (2017) How does grandparent childcare affect labor supply? IZA World Labor 2017:337. https://doi. org/10.15185/izawol.337 